\title{
EFEITO SETORIAL DA INTERMEDIAÇÃO FINANCEIRA NA DINÂMICA DA ESTRUTURA DE CAPITAL
}

\author{
ERIKA BURKOWSKI * \\ Fernanda FinotTi Cordeiro ${ }^{\dagger}$ \\ Fernando Salgueiro Perobelli ${ }^{\ddagger}$
}

\begin{abstract}
Resumo
Se empresas que atuam em setores com maior restrição financeira tendessem a ser mais conservadoras, formando uma reserva de liquidez, haveria efeitos sobre a estrutura de capital. Assim, pretende-se verificar se a sensibilidade setorial a oscilações na oferta de recursos pelo setor financeiro afeta o grau de ajustamento da estrutura de capital das empresas. Em uma amostra de 612 empresas brasileiras de capital aberto, o modelo de trade-off dinâmico é estimado pelo método de variáveis instrumentais em diferenças. Constata-se que o multiplicador financeiro setorial pode ser visto, na média, como uma medida da restrição financeira, que aumenta a importância do estoque de dívidas sobre as novas contratações, reduzindo a velocidade de ajuste das empresas à estrutura de capital ótima.
\end{abstract}

Palavras-chave: matriz de contabilidade social e financeira, insumo-produto, estrutura de capital, trade-off dinâmico, painéis dinâmicos.

\begin{abstract}
Companies that operate in sectors with greater financial restrictions tend to be more conservative, forming a liquidity reserve. In this sense, the proposal is to verify if the sectorial sensitivity to fluctuations in the supply of resources by the financial sector affects the degree of adjustment of the companies' capital structure. In a sample of 612 publicly traded Brazilian companies, the dynamic trade-off model is estimated by the method of instrumental variables in differences. It appears that the sectorial financial multiplier can be seen, on average, as a measure of financial constraint, which increases the importance of the debt stock on new hires, reducing the speed of adjusting companies to the optimal structure.
\end{abstract}

Keywords: social and financial accounting matrix, input-output, capital structure, dynamic trade-off, dynamic panels.

JEL classification: G32, R10.

DOI: http://dx.doi .org/10.11606/1980-5330/ea 150878

\footnotetext{
*Universidade Federal Fluminense. E-mail: erikab@id.uff.br

† Universidade Federal de Juiz de Fora. E-mail:fernandafinotti.perobelli@ufjf.edu.br

‡ Universidade Federal de Juiz de Fora. E-mail: fernando.perobelli@ufjf.edu.br
} 


\section{Introdução}

Questões relacionadas à oferta de recursos pelos financiadores são relevantes, embora ignoradas nos estudos relacionados à estrutura de capital em que as características das empresas demandantes são o foco da análise. Em mercados afetados por incertezas e choques de liquidez, é possível que as empresas estejam sujeitas a restrições financeiras relevantes ao tomarem suas decisões de financiamento.

Conforme destacado por Almeida \& Campelo (2007), a existência de restrições financeiras gera endogeneidade entre as decisões de investimento e financiamento, havendo, em empresas restritas, uma complementariedade entre fluxos internos e externos nas decisões de financiamento. Para essas empresas, a decisão de financiamento pode ser tomada visando formar uma reserva de liquidez capaz de financiar não apenas os projetos correntes, mas também os futuros.

Nesta situação, além de fatores relacionados à demanda de recursos pelas firmas, a estrutura de capital pode refletir questões relacionadas ao setor de atividade econômica em que a empresa atua (Copat \& Terra 2009, Martins \& Terra 2014) e questões relacionadas ao setor de intermediação financeira (La Porta et al. 1998).

A estrutura da indústria impõe e restringe o endividamento. Titman (1984) havia levantado a hipótese de que empresas que operam em indústrias muito singulares, aquelas em que o processo produtivo exige produtos e serviços muito específicos, teriam menor nível de endividamento devido aos altos custos de liquidação. Recentemente, outras características da indústria foram levantadas como potenciais determinantes do endividamento. Características como a dispersão da eficiência tecnológica, a disponibilidade de recursos no setor, o nível de concentração refletido no poder de barganha dos clientes e dos fornecedores, impõem uma determinada necessidade de recursos de terceiros para financiar o capital de giro, os investimentos e também para alavancar os resultados, aumentando o retorno e o risco dos investidores, ao mesmo tempo em que restringe a oferta de recursos, devidos aos riscos impostos pela estrutura da indústria.

Apesar de robustas as hipóteses, pouca evidência empírica foi observada, justificando a busca por variáveis que possam capturar as características setoriais. As características do setor de atuação da empresa, ou seja, da indústria, determinam uma necessidade de recursos devido à estrutura operacional e seus relacionamentos na cadeia produtiva, ao mesmo tempo em que define seu acesso ao crédito, evidenciando a restrição financeira imposta sobre a indústria. Surge assim a possibilidade de que a sensibilidade setorial ao fluxo de recursos do setor financeiro seja um fator relevante da estrutura de capital.

O fluxo de recursos entre os setores de intermediação financeira e os diversos setores de atividade econômica podem ser capturados pela metodologia insumo-produto. O fluxo de recursos entre o setor de intermediação financeira e os diversos setores revela a restrição financeira a nível setorial (onde há menor fluxo, há maior restrição) e o efeito deste fluxo no produto dos diversos setores revela a sensibilidade setorial à oferta de recursos pela intermediação financeira (o efeito do fluxo na produção). Por isso, buscou-se na metodologia insumo-produto uma medida que busca relacionar as características do setor de atuação (características da indústria) e a restrição financeira setorial a partir da análise do fluxo de recursos entre os setores. 
Na presente pesquisa, o objetivo é verificar se a sensibilidade setorial a oscilações na oferta de recursos pelo setor de intermediação financeira afeta o grau de ajustamento da estrutura de capital das empresas.

A abordagem da Matriz de Contabilidade Social e Financeira (MCSF), derivada da metodologia insumo-produto, é utilizada para a construção de multiplicadores, denominados Multiplicadores Financeiros Setoriais (MFS), os quais evidenciam o efeito que choques exógenos na demanda por recursos do setor financeiro causam na produção dos demais setores de atividade econômica. Por considerar a estrutura de fluxos intermediários de produção, expandidos para acomodar fluxos de renda e fluxos financeiros, o MFS implicitamente considera as características setoriais relacionadas à eficiência tecnológica, as interações na cadeia produtiva e a distribuição da renda, indicando como a produção dos diversos setores é afetada por choques financeiros. Tal impacto servirá como proxy para a sensibilidade dos setores produtivos a choques na oferta de recursos financeiros (sensibilidade setorial).

Como há muitas proxies constituídas para representar os diversos constructos teóricos (não observáveis) determinantes da estrutura de capital, listados na vasta literatura acerca do assunto, 48 variáveis tradicionalmente encontradas na literatura são reunidas e previamente tratadas pela análise fatorial, de onde se extraíram 9 fatores latentes que serão utilizados para determinar a estrutura de capital meta no modelo dinâmico de estrutura de capital cuja forma funcional deriva da abordagem de Dynamic Trade-Off (DTO), adaptada de Flannery \& Rangan (2006). Foi utilizado o método de variáveis instrumentais em diferenças para tratar a endogeneidade gerada pela inclusão do endividamento defasado como variável explicativa necessária para mensurar a velocidade de ajustamento da estrutura de capital em direção à meta.

As análises foram realizadas em uma amostra formada por 612 empresas brasileiras de capital aberto, listadas na Bolsa de Valores brasileira (B3), no período de 2005 a 2009, compiladas pela empresa Economatica. A definição do período se deve à limitação na divulgação das MCSF brasileiras, pois elas foram publicadas exclusivamente para o período de 2005 a $2009 .{ }^{1}$

A inclusão do indicador MFS interagindo com o endividamento defasado aponta para um aumento do coeficiente do estoque de dívida passada sobre o endividamento atual, o que indica menor velocidade de ajuste das empresas em direção a um novo nível de endividamento, revelando que a oferta de crédito pode ser considerada uma medida de restrição financeira sofrida pelas empresas (maior inércia no ajuste). Em nível das firmas, entretanto, quanto maior a interação do setor produtivo com o setor financeiro, mais essa restrição é aliviada. Ou seja, setores com maiores multiplicadores (maior relacionamento com o setor de intermediação financeira) apresentam inércia menor que os demais.

O trabalho contribui, ainda, reforçando os fatores determinantes extensivamente retratados na literatura (7 dos 9 fatores se mostraram significativos), indicando que as empresas aumentam o estoque de dívida em momentos de hot market no mercado de dívidas, reforçando a hipótese de Market Timing, e que são mais endividadas as empresas em fase de maturidade (alta geração de

\footnotetext{
${ }^{1}$ As MCSF foram publicadas somente para o período de 2005 a 2009. Estão disponíveis, juntamente com as notas metodológicas, em https://www.ufjf.br/lates/base-de-dados/mcsf-brasil2005-2009/.
} 
fluxo de caixa, baixo risco e bluechips), confirmando hipóteses subjacentes à DTO.

A próxima seção desse trabalho traz a revisão teórica sobre estrutura de capital e apresenta os fundamentos do multiplicador financeiro setorial. $\mathrm{Na}$ sequência é apresentada a análise empírica, a metodologia, a base de dados, a análise fatorial, para reduzir a quantidade de variáveis, a análise de regressão, o modelo, o método e os resultados encontrados. Nas considerações finais são destacadas as implicações dos principais resultados e as limitações do trabalho.

\section{Estrutura de Capital}

Há mais de 60 anos, busca-se entender a relevância da escolha da estrutura de capital para o valor da empresa. Os trabalhos seminais de Durand (1952) e Modigliani \& Miller $(1958,1963)$ estimularam uma crescente literatura na área. Mesmo com o grande aprimoramento das teorias, descobrimento de novas variáveis e questões relevantes para a explicação da decisão de financiamento pelas empresas e constante evolução nos métodos econométricos empregados nas análises empíricas, não há um consenso quanto aos fatores determinantes da estrutura de capital das firmas nem quanto à existência de uma estrutura de capital ótima.

Duas principais correntes teóricas buscam explicar o comportamento das firmas frente à decisão de financiamento: uma se refere a Modelos de TradeOff (Harris \& Raviv 1991) e a outra a Pecking Order Theory (Myers \& Majluf 1984).

Quanto à primeira, os modelos de Modigliani \& Miller (1963) e Schwartz \& Aronson (1967) propõem que a empresa tome sua decisão de financiamento buscando alcançar uma estrutura de capital ótima, dada pelo balanceamento entre custos e benefícios do endividamento. Ao longo dos anos, a corrente teórica de Trade-Off evoluiu de uma abordagem estática para uma abordagem dinâmica, incorporando fatores determinantes de uma estrutura de capital ótima variante no tempo e com custos de ajustamento do nível da dívida. A distância entre o nível atual e o nível desejado de financiamento gera perda de valor; entretanto, se o custo de ajustamento (gasto necessário para amortizar ou assumir dívida) superar tal perda de valor, a empresa encontra-se em melhor situação se não ajustar o nível corrente de alavancagem, atuando momentaneamente fora de sua estrutura meta. Dessa forma, a firma só deveria realocar-se ao ponto ótimo de endividamento quando as perdas provenientes do desvio desta superassem o custo de ajustamento da dívida. A abordagem do Dynamic Trade-Off (DTO) considera, além do equilíbrio entre benefícios e custos da dívida e de agência, os custos de ajustamento.

Assim, o objetivo da firma para a teoria DTO é alcançar uma trajetória ótima considerando tanto a expectativa do nível ótimo futuro como também o custo de reajustamento (Fischer et al. 1989). O modelo de Flannery \& Rangan (2006), que busca avaliar a existência de custos de ajustamento em uma abordagem dinâmica, será utilizado na análise empírica deste trabalho.

A segunda corrente teórica que busca explicar o comportamento das empresas quanto à decisão de financiamento é a Pecking Order Theory (POT), formulada inicialmente por Myers (1984) e Myers \& Majluf (1984). Segundo a POT, a existência de assimetria informacional e problemas advindos da sina- 
lização de informações privadas ao mercado justificariam uma hierarquia de preferência de fontes de financiamento. Shyam-Sunders \& Myers (1999) sugerem que as empresas não teriam qualquer meta de endividamento ótimo, mas sim que o nível de endividamento seria resultado da escolha, sob essa hierarquia de instrumentos de financiamentos, ao longo do tempo. Sob a POT, mudanças nos níveis de endividamento seriam determinadas pela necessidade de fundos externos capazes de financiar os projetos atuais da firma.

Titman \& Wessels (1988) oferecem uma síntese das relações esperadas entre o nível de alavancagem e os potenciais determinantes da demanda por financiamento:

- valor colateral dos ativos: sob DTO, empresas com ativos que podem ser usados como colaterais na obtenção de empréstimos tendem a ter maior endividamento; pela ótica dos custos de agência (Jensen \& Meckling n.d.), a existência de ativos que podem ser usados como garantia reduz o risco de expropriação da riqueza dos credores pelos gestores;

- outros benefícios fiscais que não os da dívida: sob DTO, outros benefícios fiscais que não os da dívida são substitutos aos benefícios fiscais do endividamento; assim, empresas com outras fontes de benefícios tributários, que não fossem do endividamento, tais como depreciação e amortização, tendem a ter menor nível de endividamento (DeAngelo \& Masulis 1980);

- tamanho: sob DTO, empresas maiores, mais diversificadas e maduras, tendem a ser percebidas como menos arriscadas e, consequentemente, manter um nível maior de endividamento (Warner 1977);

- volatilidade: sob DTO, o nível ótimo de endividamento da empresa é uma função decrescente da variabilidade de seus resultados operacionais, pois a volatilidade é uma medida associada ao risco (Bradley et al. 1984);

- singularidade: se refere à existência de produtos e serviços muito específicos. Titman (1984) propõe que a singularidade observada na atividade produtiva seja negativamente relacionada ao endividamento. Para o autor, empresas com ativos muito específicos têm dificuldade em oferecêlos como colaterais, reduzindo a propensão ao endividamento. Logo, precisam ser mais conservadoras, evitando o custo de falência, que geraria um alto impacto sobre seus stakeholders (trabalhadores, clientes e fornecedores) e um aumento no custo de fornecimento de insumos por esses parceiros.

A abordagem da POT diverge da DTO quanto a algumas relações empíricas observáveis:

- lucratividade e fluxo de caixa livre: sob DTO, a capacidade de geração de caixa deve ser positivamente relacionada ao nível de endividamento, uma vez que empresas lucrativas, tendem a ter menores custos de endividamento e precisam utilizar dos benefícios fiscais da dívida; já sob a POT, em sua versão original, essa relação deveria ser negativa: empresas com capacidade de gerar fundos internamente deveriam recorrer menos ao endividamento; 
- crescimento: sob DTO, o crescimento potencial da empresa levaria a níveis menores de endividamento (relação negativa), já que os custos de agência tendem a ser mais elevados para as firmas quando há maior flexibilidade e possibilidade de discricionariedade na escolha de projetos futuros por parte do gestor. Já sob a POT, empresas rentáveis e com poucas oportunidades de investimento (pouco crescimento) apresentariam baixos níveis de endividamento e firmas cujas oportunidades de investimento superassem os fundos gerados internamente utilizariam mais dívida (relação positiva entre crescimento e endividamento).

Além dos atributos tradicionalmente associados às teorias de Trade-Off e POT, há outros, associados a proposições teóricas recentes:

- qualidade da governança corporativa: a assimetria informacional cria um problema de seleção adversa ao desestimular a oferta de ações por empresas com boa governança e ao estimular a oferta de ações por empresas com governança ruim. Por conseguinte, nos mercados com baixa proteção aos acionistas minoritários, empresas com boas práticas de governança buscam outras fontes de financiamento, entre elas o endividamento, induzindo a uma relação positiva entre qualidade da governança corporativa e grau de endividamento, ceteris paribus. De maneira substitutiva, a relação entre a governança e alavancagem poderia ser negativa, considerando que uma melhora na governança desestimularia o uso da dívida para fins de efeito disciplinador. Em La Porta et al. (1998), destacam-se fatores relacionados ao desenvolvimento financeiro e qualidade institucional do mercado de capitais que tendem a ser negativamente relacionados ao endividamento bancário, pois ensejam maior facilidade de acesso a fontes alternativas e mais amplas de capital. Dessa forma, a relação entre a governança e a alavancagem não é bem definida teoricamente (Silveira 2004);

- janelas de oportunidade: de acordo com Baker \& Wurgler (2002), o Market Timing é definido como a presença de janelas de oportunidade em que o preço das ações de uma determinada empresa está incorretamente formado pelo mercado, influenciando os gestores dessa empresa em relação à decisão de financiamento. Nessa abordagem, a estrutura de capital de uma determinada empresa seria resultado de decisões cumulativas tomadas ao longo de janelas de oportunidades. A liquidez de mercado (seja de ações ou dívida) pode influenciar os custos de cada fonte de capital e, portanto, a decisão de financiamento da empresa. Como os gestores possuem informação mais completa a respeito da empresa, sabem com maior precisão se o preço da ação está correto, sub ou sobrevalorizado. Então, esperam pela existência de janelas de oportunidade para tomar a decisão entre a utilização de recursos próprios, emissão de ações ou contratação de dívidas (Jiménez 2007). Quando o valor de mercado da empresa está baixo em relação ao seu valor patrimonial, os gestores tendem a buscar financiamento pela emissão de dívida;

- idade/maturidade: a empresa que se apresenta em fase de maturidade dispõe de melhores condições de crédito, enquanto aquela mais recente, ainda em fase de crescimento, não estabelecida e sem classificação de 
crédito, possui menor credibilidade e acessa piores condições na contratação de dívida. Esta abordagem, relacionada ao ciclo de vida, observada nos trabalhos de Berger \& Udell (1998) e Fluck et al. (1998), enseja um comportamento passivo das decisões gerenciais. A relação entre potencial de crescimento (associado à fase do ciclo em que a empresa se encontra) e dívida poderia ser negativa por questões associadas à facilidade e acessibilidade ao crédito (restrição financeira).

Acessibilidade ao crédito remete a restrição financeira. Estimulados pelas descobertas de Fazzari et al. (1988) quanto à sensibilidade dos investimentos ao fluxo de caixa, Almeida \& Campelo (2007) propõem uma modificação na versão original da POT, devido à presença de restrição financeira.

Segundo a POT original, num cenário de assimetria informacional, se uma firma alcançasse altos lucros, sua reação seria diminuir a demanda por fundos externos, incluindo a dívida, seja por meio da substituição de recursos tomados emprestados por recursos próprios nos novos investimentos, seja via amortização da dívida antiga. O mesmo resultado, entretanto, não é esperado na versão da POT com restrição financeira.

Para Almeida \& Campelo (2007), três efeitos diferentes são usados para explicar a relação neutra, ou positiva, entre financiamento externo e fundos internos num contexto de restrição. Primeiro, uma empresa restrita poderia usar recursos internos para aumentar gastos de capital ao invés de reduzir a utilização de recursos externos, dado o alto custo de oportunidade do investimento perdido. Segundo, uma firma que é financeiramente restrita não se preocupa apenas com o financiamento de investimentos correntes, mas também com os investimentos futuros. A necessidade de financiar projetos futuros sob restrição de crédito aumenta a demanda (preventiva) da empresa tanto por ativos líquidos (caixa), como por capital externo. Por último, os altos custos de financiamento externo geram uma complementaridade direta entre a geração interna de caixa e a capacidade da firma restrita de obter recursos externos, já que uma empresa com restrições financeiras, mas com alta geração de recursos, pode direcionar parte desses recursos para investimentos em ativos colateralizáveis, capazes de aumentar os colaterais da firma e sua capacidade de obtenção de recursos adicionais. Estes novos recursos externos serão novamente direcionados a ativos colateralizáveis, ampliando o efeito positivo dos recursos internos na demanda por recursos externos (multiplicador de crédito).

Os três efeitos apontam na mesma direção: observando aumentos na geração de caixa, uma empresa financeiramente restrita poderia não reduzir, mas aumentar sua preferência por recursos externos. A empresa restrita, controlando por outros fatores, possui melhor alocação para recursos adicionais (mais investimentos colateralizáveis ou ativos líquidos) e poderia achar ótimo aumentar sua demanda por recursos externos precisamente em momentos em que a geração de fundos internos é alta. Assim a relação entre lucratividade ou fluxo de caixa livre e endividamento poderia ser positiva.

Como citado anteriormente a singularidade é uma característica da indústria, do setor de atuação da empresa. Titman (1984) sugere que empresas cujos produtos exigem serviços e processos muito específicos incorrem em maiores custos de liquidação. Titman \& Wessels (1988) utilizam uma dummy para o setor de produção de bens de capital, para capturar essa característica da indústria. Frank \& Goyal (2003) e Flannery \& Rangan (2006) utilizam a alavanca- 
gem setorial média para capturar a especificidade do setor. Se a singularidade cria uma limitação na oferta de recursos, pode ser considerada uma medida de restrição financeira, de forma que setores muito singulares sofrem maior restrição financeira. Neste sentido, a alavancagem setorial também pode refletir questões de restrição financeira a nível setorial.

MacKay \& Philips (2005), buscam aprofundar o entendimento das relações das indústrias sobre a estrutura de capital utilizando modelos de equilíbrio parcial, como o de Maksimovic \& Zechner (1991). De acordo com o modelo proposto, a dispersão da eficiência tecnológica deve ser positivamente relacionada com a alavancagem setorial. Empresas com produção mais eficiente e de melhor qualidade apresentam maior rentabilidade, enquanto que empresas menos eficientes apresentam menor rentabilidade. Para equiparar seu retorno e seguirem competitivas no mercado, as últimas devem aumentar seu endividamento. No equilíbrio, a dispersão da eficiência tecnológica deve ser positivamente relacionada com endividamento.

O nível de concentração da indústria também pode afetar a estrutura de capital, pois em setores cujos clientes e fornecedores exercem pressão maior sobre a empresa, o endividamento pode ser deliberadamente aumentado para que uma parcela de seus fluxos de caixa seja comprometida com os credores e ela sofra menos pressão das demais partes. As empresas podem decidir aumentar seu endividamento como forma de diminuir o poder dos agentes interessados (stakeholders) não financeiros. Logo, elas utilizariam o endividamento como escudo para a potencial extração futura de divisas por parte dos agentes interessados não financeiros. Portanto, espera-se uma relação positiva entre o poder de barganha dos clientes e o poder de barganha dos fornecedores e o endividamento (Kale \& Shahrur 2007).

Adicionalmente, Kayo \& Kimura (2011) destacam que a liquidez do setor pode afetar a estrutura de capital. Para representar esta característica, propõem a munificência (medida da disponibilidade dos recursos no setor) e o dinamismo (medida da volatilidade dos recursos disponíveis no setor) para representar a liquidez do setor. Setores com maior disponibilidade de recursos comportam maior crescimento das empresas que, dessa forma, apresentam maior lucratividade. A lucratividade influenciará a alavancagem positivamente se a DTO ou a POT com restrição vigorar e negativamente se a POT original vigorar.

A estrutura da indústria, ou seja, as características do setor de atuação da empresa, determinam uma necessidade de recursos devido às suas necessidades operacionais e seus relacionamentos na cadeia produtiva, ao mesmo tempo em que definem o acesso ao crédito, evidenciando a restrição financeira imposta à indústria. Surge assim a possibilidade de que a sensibilidade setorial aos recursos do setor financeiro seja um fator determinante da estrutura de capital.

Relacionando o setor de atuação à restrição financeira, a hipótese seria de que quanto maior a dependência dos setores produtivos em relação ao setor financeiro em uma economia (seja para aumentar a rentabilidade ou para reduzir o fluxo de caixa livre), maior deveria ser a tendência desses setores a manter um estoque de dívida elevado e permanente (maior inércia), carregando tal estoque por períodos maiores de tempo, de forma conservadora e com maiores custos de carregamento. Dessa forma a velocidade de ajustamento da estrutura de capital tenderia a ser menor em setores mais sensíveis ao setor financeiro. O próximo tópico apresenta uma medida proposta para 
mensurar a sensibilidade setorial.

\subsection{Multiplicador Financeiro Setorial}

Multiplicadores do produto são derivados da metodologia insumo-produto ${ }^{2}$ (Leontief 1936) e se destinam a capturar o efeito de choques na demanda de um determinado setor (neste caso, do setor de intermediação financeira) sobre o produto dos demais setores de atividade econômica. Em outras palavras, multiplicadores do produto evidenciam a sensibilidade setorial a oscilações na oferta de recursos.

O multiplicador do produto utilizado neste trabalho, denominado Multiplicador Financeiro Setorial (MFS), foi calculado a partir das Matrizes de Contabilidade Social e Financeira (MCSF) brasileiras. Uma MCSF evidencia todo o fluxo circular da renda na economia, a geração de renda pela produção dos diversos setores de atividade econômica, as relações na cadeia produtiva que estão expressas nas transações intersetoriais, a distribuição da renda entre os setores institucionais (empresas, famílias, governo), a distribuição entre consumo e poupança, os investimentos fixos (formação bruta de capital fixo e variação de estoques), os investimentos financeiros realizados (variação de ativos financeiros: aplicações em depósitos, títulos, ações), as fontes de fundos obtidas (variação de passivos financeiros: obtenção de empréstimos, emissão de títulos, emissão de ações) e, ainda, as transações de bens, serviços e fundos com o exterior. Portanto, o MFS captura as relações da cadeia produtiva expressas no fluxo de transações produtivas entre os diversos setores, as relações de distribuição da renda na economia e as relações de financiamento dos investimentos.

As MCSF brasileiras apresentam as transações econômicas detalhadas em 110 bens e serviços, 55 setores de atividade econômica, 3 fatores de produção, 4 setores institucionais nas contas corrente e capital e 7 instrumentos financeiros na conta financeira e uma conta de resto do mundo. Elas foram construídas a partir de três base de dados:

1. Matrizes Insumo-Produto brasileiras (Guilhoto et al. 2005), disponibilizadas pelo Instituto Brasileiro de Geografia e Estatística (IBGE) e pelo Núcleo de Economia Regional e Urbana da Universidade de São Paulo (NEREUS/USP);

2. Contas Econômicas Integradas (CEI), publicadas pelo IBGE;

3. Conta Financeira e Conta de Patrimônio Financeiro, elaboradas em conjunto pelo Banco Central do Brasil (BACEN) e pelo IBGE como parte integrante das CEI.

A metodologia insumo-produto considera coeficientes fixos de produção, com retornos de escala constante. Estabelece relações lineares entre as transações econômicas, garantindo que as relações econômicas estruturais, neste caso fluxo de produção, renda e fundos, sejam mantidas constantes, permitindo a simulação do impacto no produto causado por variações na demanda.

\footnotetext{
${ }^{2}$ Miller \& Blair (2009) apresentam um amplo referencial teórico sobre a Metodologia InsumoProduto, Aplicações para a economia brasileira podem ser vistas em Guilhoto (2004).
} 
Uma variação exógena na demanda percorre o caminho dos fluxos (os coeficientes fixos), causando alguma variação no produto. A mensuração da variação causada no produto representa o impacto no produto.

Para calculo do MFS, obtém-se a matriz inversa de Leontief da MCSF, aplicando a expansão pelo fator externo (Miyazawa 1976). O fator externo Miyazawa é definido conforme a Equação (1):

$$
F_{11}=\left[I-\left(I-A^{S A M}\right)^{-1} A_{12} A_{21}\right]^{-1}\left(I-A^{S A M}\right)^{-1}
$$

onde:

$A^{S A M}=$ Matriz de Coeficientes Técnicos da Matriz de Contabilidade social, inclui a Matriz insumo-Produto (transações intersetoriais), a Conta Corrente (renda) e a Conta Capital (formação bruta de capital fixo);

$A_{12}=$ Matriz de Coeficientes Técnicos da Variação de Ativos;

$A_{21}=$ Matriz de Coeficientes Técnicos da Variação de Passivos.

O resultado da aplicação do fator externo de Miyazawa é uma matriz de multiplicadores, os quais evidenciam o efeito de mudanças dos ativos e passivos financeiros $\left(A_{12}\right.$ e $\left.A_{21}\right)$, na economia real.

Selecionando a coluna referente ao setor de intermediação financeira, na matriz de multiplicadores, cada valor constante neste vetor indica qual será a variação do produto dos setores (que estão nas linhas), dada uma variação exógena de uma unidade monetária na demanda agregada sobre o setor de intermediação financeira. Ou seja, quanto o aumento de \$1 demandado gera de 'produção' no setor de intermediação financeira e como esse aumento na 'produção' de serviços no setor financeiro se espalha para os demais setores produtivos, afetando a produção de cada um deles.

Indicando o efeito da variação na demanda do setor financeiro e deste sobre o produto dos demais setores, o MFS representa a sensibilidade dos demais setores às variações no fluxo de fundos do setor de intermediação financeira.

Como o MFS é calculado a partir de uma matriz de fluxos efetivamente transacionados e os fluxos são definidos pela estrutura da indústria, pela estrutura de distribuição de renda e alocação de recursos financeiros, características setoriais como singularidade, dispersão da eficiência tecnológica, concentração e liquidez implícitas nos relacionamentos da cadeia produtiva, bem como aspectos relacionados à restrição financeira, são capturadas pelo MFS.

Assim, propõe-se que o MFS represente a sensibilidade setorial a oscilações na oferta de recursos e seja considerado uma potencial medida de restrição financeira. Como defendem Almeida \& Campelo (2007), na presença de restrição financeira, as empresas precisarão alterar seus planos de investimento conforme a oferta de financiamento. Ampliando a análise a nível setorial, a hipótese é que empresas atuantes em setores mais sensíveis aos fluxos do setor financeiro terão que alterar seus planos de investimento conforme a oferta de financiamento. Logo, a sensibilidade setorial a oscilações na oferta de recursos afetará a decisão de estrutura de capital e o grau de ajustamento, reduzindo a velocidade de ajuste das empresas em direção à estrutura ótima devido ao aumento da importância do estoque de dívidas sobre novas contratações. 


\section{Análise Empírica}

A base de dados utilizada foi obtida do sistema Economatica e caracteriza-se por um painel não balanceado, composto seccionalmente por 612 empresas de capital aberto, com ações negociadas no Brasil, na Bolsa de Valores brasileira (B3), distribuídas longitudinalmente em 20 períodos trimestrais compreendidos entre janeiro de 2005 e dezembro de 2009, totalizando 7.095 observações. O período utilizado foi limitado à disponibilidade das MCSF brasileiras, pois elas foram publicadas somente para o período de 2005 a 2009 devido à descontinuidade na divulgação das contas financeiras e contas de patrimônio financeiro ${ }^{3}$ pelo IBGE.

A variável dependente é o endividamento atual (no período $t$ ), formado pelo quociente entre dívidas (passivo total menos patrimônio líquido) e ativo total. Observa-se que a média do endividamento é superestimada devido à existência de $1 \%$ da amostra com endividamento extremamente elevado. Provavelmente empresas em início de processo de falência. Optou-se por manter essas empresas na amostra, bem como as empresas com patrimônio líquido negativo, para não gerar viés de sobrevivência ${ }^{4}$.

Considerando a mediana, pode-se dizer que as empresas brasileiras tendem a manter 58 por cento de capital de terceiros em sua estrutura de capital. Ademais, 14 por cento das empresas apresentam endividamento maior que 1 (Patrimônio Líquido negativo).

A Tabela 1 apresenta a distribuição do endividamento ao longo dos anos. Pode-se observar que a média de endividamento das empresas se reduz no ano de 2006 e aumenta nos anos seguintes (2007 a 2009). A maior variação ocorre no ano de 2008, em decorrência da adoção de medidas anticíclicas pelo Governo, que ampliaram o crédito ao consumo e ao investimento. Nesse ano, houve aumento na média, na mediana, no desvio padrão e no valor máximo do endividamento das empresas. Em 2009, a média volta a se reduzir, mas o desvio padrão e o valor máximo aumentam.

Tabela 1: Estatísticas Descritivas do Endividamento por ano

\begin{tabular}{cccccc}
\hline Ano & Média & Desvio Padrão & $\mathbf{1}^{\mathbf{0}}$ Quartil & Mediana & $\mathbf{3}^{\mathbf{0}}$ Quartil \\
\hline 2005 & 2,39 & 16,22 & 0,41 & 0,59 & 0,82 \\
2006 & 1,98 & 9,95 & 0,42 & 0,58 & 0,79 \\
2007 & 2,11 & 13,12 & 0,39 & 0,55 & 0,75 \\
2008 & 2,47 & 17,36 & 0,41 & 0,58 & 0,75 \\
2009 & 2,29 & 19,88 & 0,43 & 0,58 & 0,77 \\
\hline
\end{tabular}

Fonte: Elaboração própria.

O endividamento e o patrimônio líquido (cuja soma é igual ao valor do ativo total) são avaliados pelo seu valor contábil. Esta medida é utilizada por Shyam-Sunders \& Myers (1999), Fama \& French (2002), entre outros, com o objetivo de mitigar a variabilidade gerada pelas oscilações no valor de mercado das ações no patrimônio a mercado (Welch 2011).

\footnotetext{
${ }^{3}$ Atualmente as Contas Financeiras e de Patrimônio Financeiro estão sendo publicadas como parte integrante da CEI.

${ }^{4}$ Teste de robustez foi realizado considerando a retirada de empresas com PL negativo. Os sinais se mantiveram, alterando apenas a magnitude dos coeficientes.
} 
Após extensiva revisão da literatura de estrutura de capital, foram levantadas 48 variáveis de controle, além do endividamento, 40 delas referentes à empresa e 8 ao setor de atuação da empresa.

A descrição das variáveis originais se encontra na Tabela 2.

As 40 variáveis relacionadas às empresas são candidatas a proxies para constructos teóricos normalmente associados à decisão de financiamento em nível da firma (tamanho, crescimento, benefícios fiscais, etc.). Por se tratarem tais constructos de conceitos latentes (não diretamente observáveis), a exemplo de Titman \& Wessels (1988), buscou-se antes relacionar as variáveis observadas a esses constructos por meio da técnica de Análise Fatorial. A Análise Fatorial revelou existirem 9 fatores latentes às variáveis observadas, capazes de manter as características (variância) de grande parte das variáveis originais.

As 8 variáveis relacionadas ao setor de atuação, dentre elas o MSF, foram inseridas individualmente no modelo, dada sua importância nessa análise e devido ao fato de terem sido pouco discutidas na literatura de estrutura de capital. Não há evidências robustas quanto à influência delas na decisão de estrutura de capital, como apontado por Kale \& Shahrur (2007) e por Kayo \& Kimura (2011). Entretanto, somente alanvancagem setorial se apresentou significativa (e somente no modelo sem o MFS).

Como já descrito, o MFS foi obtido a partir das MCSF brasileiras e, portanto, sua periodicidade é anual. Para que pudessem ser utilizados em conjunto com os demais dados, cuja periodicidade é trimestral, foi criada uma variável de interação entre o multiplicador (sensibilidade do setor de atuação da empresa ao setor financeiro) e o grau de endividamento defasado (em $t-1$ ) da empresa. Essa variável busca medir quão sensível o setor produtivo é ao setor financeiro e como a empresa enfrenta tal sensibilidade ao tomar dívida.

A alocação dos multiplicadores à base de dados das empresas foi feita pela codificação dos setores de atividade econômica. Para tal, os setores de atuação das empresas informados pelo Sistema Norte Americano de Classificação da Indústria (NAICS 313), utilizado no sistema Economatica, foram traduzidos para a codificação do Código Nacional de Atividades Econômicas (CNAE, 2.0). Posteriormente, compilados e reduzidos para a classificação dos 55 setores produtivos da Tabela de Recursos e Usos (TRU) utilizados na Matriz de Contabilidade Social e Financeira (MCSF).

A Tabela 3, apresenta o valor do Multiplicador Financeiro Setorial (MFS) por ano para cada um dos 55 setores de atividade econômica, a média e o desvio padrão do MFS ao longo dos 5 anos (2005 a 2009). Organizados em ordem crescente da média pode-se observar os setores com menor multiplicador na parte superior da tabela e os setores com maior multiplicador na parte inferior.

O valor da soma apresentado na última linha da Tabela 3 é a variação no produto total da economia dada a variação de uma unidade na demanda da intermediação financeira. Observa-se que há uma redução do impacto do setor de intermediação financeira nos demais setores entre 2005 e 2007 (anos sem restrição), seguido de aumento em 2008 e 2009 (anos de restrição). Isso indica que, em períodos mais turbulentos, o impacto do setor financeiro nos demais setores é maior. 
Tabela 2: Descrição das Variáveis

\begin{tabular}{|c|c|c|c|c|}
\hline \multirow{2}{*}{$\begin{array}{l}\text { Constructo } \\
\text { Teórico de } \\
\text { Interesse } \\
\end{array}$} & \multicolumn{2}{|c|}{ Sinal/ Referência } & \multirow[t]{2}{*}{ Regressor } & \multirow{2}{*}{$\begin{array}{c}\text { Variável Observada } \\
\text { (candidata a representar } \\
\text { o Constructo) }\end{array}$} \\
\hline & Dynamic Trade-Off & Pecking Order Theory & & \\
\hline Tangibilidade & $\begin{array}{c}(+) \text { Harris \& Raviv (1991); } \\
\text { Shyam-Sunders \& Myers (1999) }\end{array}$ & $\begin{array}{l}\text { (-)Harris \& Raviv (1991); } \\
\text { Frank \& Goyal (2003) }\end{array}$ & $\mathrm{TANG}_{i t}$ & $\begin{array}{l}\text { Valor do Ativo Imobilizado } \\
\text { sobre o Ativo Total (AT) }\end{array}$ \\
\hline $\begin{array}{ll}\text { Debt } & \text { Tax } \\
\text { Shields } & \end{array}$ & $\begin{array}{c}\text { (+)Harris \& Raviv (1991), } \\
\text { Shyam-Sunders \& Myers (1999) }\end{array}$ & & FISC $_{i t}$ & $\begin{array}{l}\text { Razão entre o LAIR (lucro } \\
\text { antes do imposto de renda) } \\
\text { e as Receitas }\end{array}$ \\
\hline $\begin{array}{l}\text { Non-debt } \\
\text { Tax Shields }\end{array}$ & $(+)$ Harris \& Raviv (1991) & & NTAX $_{i t}$ & $\begin{array}{l}\text { Razão entre depreciação e } \\
\text { ativo total }\end{array}$ \\
\hline \multirow{3}{*}{$\begin{array}{l}\text { Oportunidade } \\
\text { de Cresci- } \\
\text { mento }\end{array}$} & \multirow{3}{*}{ (-)Jensen \& Meckling (n.d.) } & $\begin{array}{c}\text { (+)Frank \& Goyal (2003) - } \\
\text { POT Simples }\end{array}$ & $\mathrm{MTB}_{i t}$ & $\begin{array}{l}\text { Q de Tobin - razão en- } \\
\text { tre o valor de mercado da } \\
\text { empresa e o valor contábil } \\
\text { (market-to-book) }\end{array}$ \\
\hline & & \multirow{2}{*}{$\begin{array}{l}\text { (-)Fama \& French (2002) - } \\
\text { POT complexa }\end{array}$} & VARREV $_{i t}$ & $\begin{array}{l}\text { Variação percentual das Re- } \\
\text { ceitas Operacionais }\end{array}$ \\
\hline & & & VARTA $_{i t}$ & $\begin{array}{l}\text { Variação percentual do } \\
\text { Ativo Total }\end{array}$ \\
\hline Singularidade & $\begin{array}{c}\text { (-)Harris \& Raviv (1991); } \\
\text { Shyam-Sunders \& Myers (1999) }\end{array}$ & & SALES_REV $_{i t}$ & $\begin{array}{l}\text { Razão entre Despesas com } \\
\text { vendas/Receita bruta }\end{array}$ \\
\hline \multirow{3}{*}{$\begin{array}{l}\text { Tamanho da } \\
\text { empresa }\end{array}$} & \multirow{3}{*}{$\begin{array}{l}\text { (+)Harris \& Raviv (1991); } \\
\text { Rajan \& Zingales (1995) }\end{array}$} & \multirow{3}{*}{$\begin{array}{c}\text { (-) Ross (1977); } \\
\text { Harris \& Raviv (1991); } \\
\text { Rajan \& Zingales (1995) }\end{array}$} & $\mathrm{LNREV}_{\text {it }}$ & $\begin{array}{l}\text { Logaritmo Neperiano das } \\
\text { Receitas Operacionais }\end{array}$ \\
\hline & & & LNTA $_{i t}$ & LN (AtivoTotal) \\
\hline & & & $\mathrm{LNE}_{i t}$ & LN (Patrimônio Líquido) \\
\hline \multirow{2}{*}{$\begin{array}{l}\text { Volatilidade/ } \\
\text { Risco }\end{array}$} & \multirow[b]{2}{*}{ (-)Shyam-Sunders \& Myers (1999) } & \multirow[b]{2}{*}{$(*)$} & SDEBITDA $_{i t}$ & $\begin{array}{lll}\text { Desvio } & \text { padrão } & \text { do } \\
\text { EBITDA }^{5} & & \end{array}$ \\
\hline & & & $\mathrm{SDOP}_{i t}$ & $\begin{array}{l}\text { Desvio padrão do Lucro } \\
\text { Operacional }\end{array}$ \\
\hline
\end{tabular}

Fonte: Elaboração própria.

${ }^{5}$ Earnings Before Interests, Tax and Depreciation (EBITDA) representa, representa o resultado estritamente operacional, o Lucro antes de Juros, Impostos e Depreciação. 
Tabela 2: Descrição das Variáveis (continuação)

\begin{tabular}{|c|c|c|c|c|}
\hline \multirow{2}{*}{$\begin{array}{l}\text { Constructo } \\
\text { Teórico de } \\
\text { Interesse } \\
\end{array}$} & \multicolumn{2}{|c|}{ Sinal/ Referência } & \multirow[t]{2}{*}{ Regressor } & \multirow{2}{*}{$\begin{array}{c}\text { Variável Observada } \\
\text { (candidata a representar } \\
\text { o Constructo) }\end{array}$} \\
\hline & Dynamic Trade-Off & Pecking Order Theory & & \\
\hline \multirow{4}{*}{ Lucratividade } & \multirow{4}{*}{ (+)Harris e Raviv (1991) } & \multirow{4}{*}{ (-)Rajan \& Zingales (1995) } & $\mathrm{MGOP}_{i t}$ & $\begin{array}{l}\text { Margem Lucro Operacio- } \\
\text { nal }\end{array}$ \\
\hline & & & $\mathrm{ROA}_{i t}$ & Lucro Líquido / AT \\
\hline & & & $\mathrm{MARG}_{i t}$ & $\begin{array}{l}\text { Margem (Lucro Líquido / } \\
\text { Vendas) }\end{array}$ \\
\hline & & & TURN $_{i t}$ & Giro (Vendas / AT) \\
\hline \multirow[b]{2}{*}{ Liquidez } & \multirow[b]{2}{*}{ (+)Harris \& Raviv (1991) } & \multirow[b]{2}{*}{$\left({ }^{*}\right)$} & $\mathrm{LIQA}_{i t}$ & $\begin{array}{l}\text { Liquidez Contábil - Razão } \\
\text { entre ativo circulante e pas- } \\
\text { sivo circulante }\end{array}$ \\
\hline & & & $\mathrm{DISP}_{i t}$ & $\begin{array}{l}\text { Razão entre as Disponibi- } \\
\text { lidades da empresa (Caixa, } \\
\text { Aplicações Financeiras) e } \\
\text { Ativo Total }\end{array}$ \\
\hline \multirow[t]{2}{*}{$\begin{array}{l}\text { Liquidez em } \\
\text { Bolsa }\end{array}$} & \multirow[t]{2}{*}{ (+)Harris \& Raviv (1991) } & \multirow[t]{2}{*}{$\left({ }^{*}\right)$} & $\mathrm{LIQB}_{i t}$ & $\begin{array}{l}\text { Mede a liquidez das ações } \\
\text { das empresas na Bolsa de } \\
\text { Valores de São Paulo (Bo- } \\
\text { vespa) }\end{array}$ \\
\hline & & & VOLNEG $_{i t}$ & $\begin{array}{l}\text { Volume de negócios no } \\
\text { mercado }\end{array}$ \\
\hline \multirow[b]{2}{*}{ Maturidade ${ }^{6}$} & \multirow{2}{*}{$\begin{array}{c}\text { (+)Fluck et al. (1998) } \\
\text { De acordo com a teoria de } \\
\text { Ciclo de Vida Financeiro }\end{array}$} & & $\mathrm{AGE}_{i t}$ & Idade da empresa \\
\hline & & & IPOAGE $_{i t}$ & $\begin{array}{l}\text { Idade da empresa a partir } \\
\text { do IPO }\end{array}$ \\
\hline \multirow{2}{*}{$\begin{array}{l}\text { Distribuição } \\
\text { de } \\
\text { Resultados }^{7}\end{array}$} & \multirow[b]{2}{*}{$\left({ }^{*}\right)$} & \multirow[b]{2}{*}{$\left({ }^{*}\right)$} & DISTRIB $_{i t}$ & $\begin{array}{l}\text { (Dividendos + Juros Sobre } \\
\text { Capital Próprio) / Patrimô- } \\
\text { nio Líquido }\end{array}$ \\
\hline & & & VARE_REV $i t$ & $\begin{array}{l}\text { Razão entre Lucro do exer- } \\
\text { cício (variação no Patrimô- } \\
\text { nio Líquido) e Receitas com } \\
\text { Vendas }\end{array}$ \\
\hline
\end{tabular}
o Constructo)

Fonte: Elaboração própria.

${ }^{6}$ As variáveis de idade foram medidas em meses desde a criação da empresa (AGE) e meses desde a abertura do capital - Oferta Inicial (IPO). Os dados foram coletados a partir do Cadastro Nacional de Pessoa Jurídica (CNPJ) da empresa e pela ficha da empresa na Comissão de Valores Mobiliários (CVM).

${ }^{7}$ A construção da variável DISTRIB exigiu certo cuidado. Optou-se pela utilização dos valores absolutos de Dividendos e JSCP para que ambas pudessem ser somadas. Além disso, decidiu-se pela razão entre os valores distribuídos e o patrimônio líquido, caracterizando o yield de distribuição. 
Tabela 2: Descrição das Variáveis (continuação)

\begin{tabular}{|c|c|c|c|}
\hline $\begin{array}{l}\text { Constructo } \\
\text { Teórico de } \\
\text { Interesse }\end{array}$ & Sinal/ Referência & Regressor & $\begin{array}{c}\text { Variável Observada } \\
\text { (candidata a representar } \\
\text { o Constructo) }\end{array}$ \\
\hline \multirow{5}{*}{$\begin{array}{l}\text { Governança } \\
\text { Corporativa }\end{array}$} & \multirow{5}{*}{$(+)$ Silveira (2004) } & SEG_NM $i t$ & $\begin{array}{l}\text { Dummy que apresenta valor } 1 \text { se a empresa per- } \\
\text { tence ao Segmento de Novo Mercado da BMF- } \\
\text { Bovespa }\end{array}$ \\
\hline & & $\mathrm{SEG} \mathrm{N}_{i t}$ & $\begin{array}{l}\text { Dummy que apresenta valor } 1 \text { se a empresa per- } \\
\text { tence ao Segmento de Nível } 1 \text { de Governança Cor- } \\
\text { porativa da BMF-Bovespa }\end{array}$ \\
\hline & & SEG_N2 ${ }_{i t}$ & $\begin{array}{l}\text { Dummy que apresenta valor } 1 \text { se a empresa per- } \\
\text { tence ao Segmento de Nível } 2 \text { de Governança Cor- } \\
\text { porativa da BMF-Bovespa }\end{array}$ \\
\hline & & $\mathrm{CONC}_{i t}$ & $\begin{array}{l}\text { Soma do percentual das ações da empresa de pro- } \\
\text { priedade dos acionistas marcados como "grupo } \\
\text { controlador" na CVM }\end{array}$ \\
\hline & & $\mathrm{CONC}_{2}$ it & $\begin{array}{l}\text { Soma do percentual das ações da empresa cujos } \\
\text { acionistas possuem pelo menos } 5 \% \text { de proprie- } \\
\text { dade }\end{array}$ \\
\hline \multirow{6}{*}{$\begin{array}{l}\text { Janelas de } \\
\text { Oportuni- } \\
\text { dade }\end{array}$} & \multirow{6}{*}{ (+)Baker \& Wurgler (2002) } & RETIBOV $_{i t}$ & Retorno da IBOVESPA no ano \\
\hline & & RETSTOCK $_{i t}$ & Retorno da Ação no ano \\
\hline & & VARBONDS $_{i t}$ & $\begin{array}{l}\text { Variação percentual do número de Debêntu- } \\
\text { res/CP emitidos no ano }\end{array}$ \\
\hline & & $\mathrm{EXPOL}_{i t}$ & $\begin{array}{l}\text { Variável Dummy para períodos de políticas ex- } \\
\text { pansionistas adotadas pelo Governo Federal }\end{array}$ \\
\hline & & QUALD $_{i t}$ & $\begin{array}{l}\text { Qualidade da Dívida - variável Dummy para } \\
\text { custo da dívida: igual a } 1 \text { se o retorno operacional } \\
\text { (LAIR/AT) for maior que [(Despesas financeiras) } \\
\text { em t/(Passivo Total - PL) em t-1] }\end{array}$ \\
\hline & & $\mathrm{KD}_{i t}$ & $\begin{array}{l}\text { Custo da dívida: (Despesas financeiras) em t / } \\
\text { (Endividamento total) em } \mathrm{t}-1\end{array}$ \\
\hline
\end{tabular}


Tabela 2: Descrição das Variáveis (continuação)

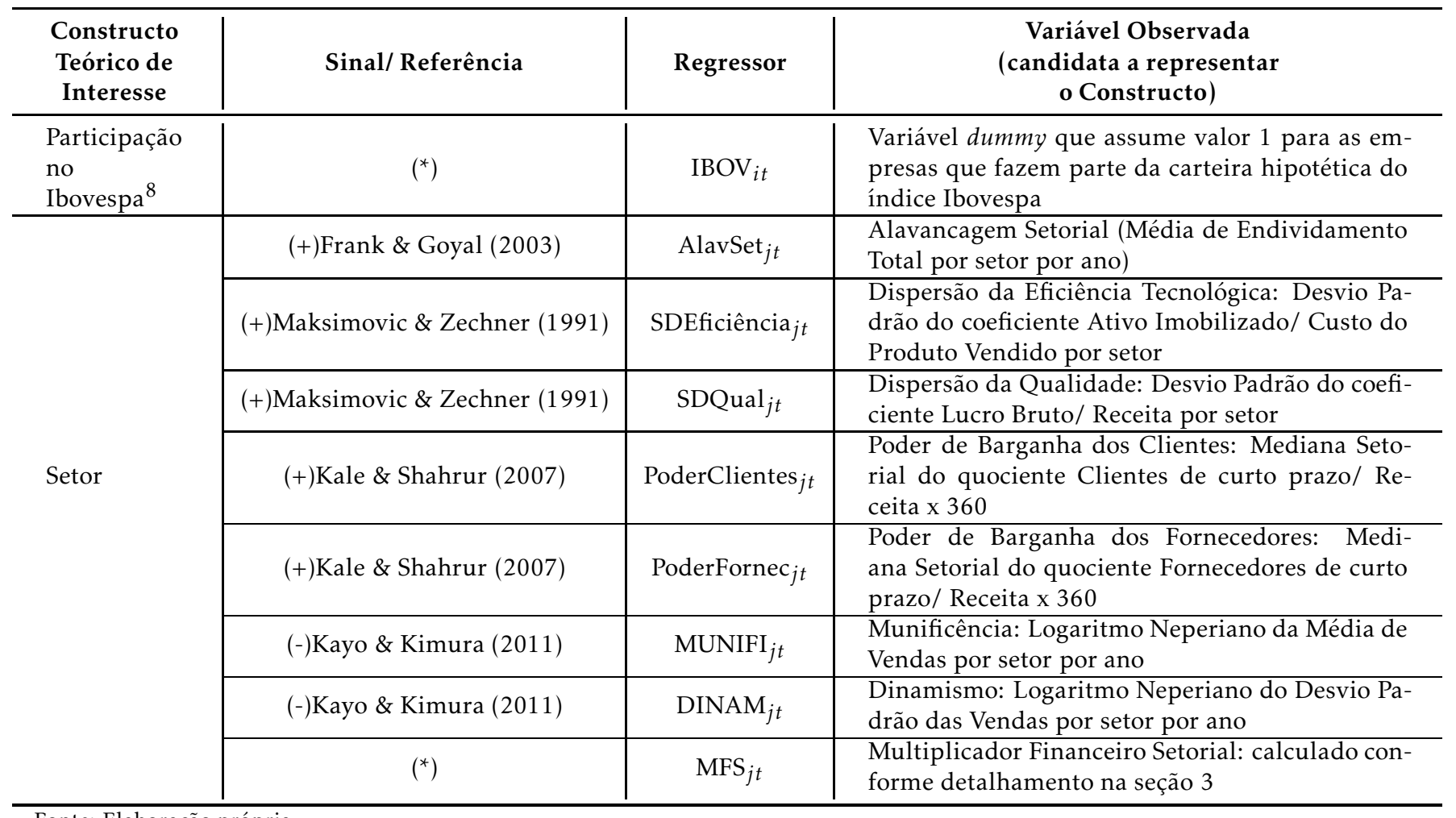

Fonte: Elaboração própria.

A variável teve como parâmetro o Índice Bovespa de setembro/2013. Este índice é atualizado a cada 4 meses pela B3, enquanto a amostra utilizada neste trabalho apresenta dados trimestrais. Além disso, a atualização tem como principal componente a alteração do "peso" de cada ação no índice, de modo que as empresas contempladas pouco variam. Dessa forma, definiu-se pela utilização de um único período como parâmetro, sob a argumentação de que pouca informação seria perdida com este procedimento. 
Tabela 3: Multiplicador Financeiro Setorial (MFS) por Setor de Atividade Econômica e por ano

\begin{tabular}{|c|c|c|c|c|c|c|c|}
\hline $\begin{array}{l}\text { Multiplicador Financeiro } \\
\text { Setorial/ Ano }\end{array}$ & 2005 & 2006 & 2007 & 2008 & 2009 & Média & Desvio \\
\hline Educação pública & 0,0004 & 0,0003 & 0,0003 & 0,0004 & 0,0004 & 0,0004 & 0,0000 \\
\hline Saúde pública & 0,0013 & 0,0008 & 0,0007 & 0,0009 & 0,0010 & 0,0010 & 0,0002 \\
\hline Minério de ferro & 0,0028 & 0,0029 & 0,0029 & 0,0023 & 0,0014 & 0,0025 & 0,0006 \\
\hline Cimento & 0,0041 & 0,0044 & 0,0035 & 0,0037 & 0,0059 & 0,0043 & 0,0009 \\
\hline $\begin{array}{l}\text { Tintas, vernizes, esmaltes e } \\
\text { lacas }\end{array}$ & 0,0048 & 0,0046 & 0,0043 & 0,0043 & 0,0055 & 0,0047 & 0,0005 \\
\hline $\begin{array}{l}\text { Outros da indústria extra- } \\
\text { tiva }\end{array}$ & 0,0048 & 0,0049 & 0,0049 & 0,0052 & 0,0064 & 0,0052 & 0,0006 \\
\hline Produtos do fumo & 0,0049 & 0,0047 & 0,0041 & 0,0040 & 0,0038 & 0,0043 & 0,0005 \\
\hline Defensivos agrícolas & 0,0059 & 0,0050 & 0,0057 & 0,0065 & 0,0063 & 0,0059 & 0,0006 \\
\hline Eletrodomésticos & 0,0061 & 0,0061 & 0,0061 & 0,0056 & 0,0070 & 0,0062 & 0,0005 \\
\hline $\begin{array}{l}\text { Aparelhos/instrumentos } \\
\text { médico-hospitalar }\end{array}$ & 0,0062 & 0,0060 & 0,0060 & 0,0058 & 0,0071 & 0,0062 & 0,0005 \\
\hline Álcool & 0,0064 & 0,0071 & 0,0078 & 0,0085 & 0,0087 & 0,0077 & 0,0010 \\
\hline $\begin{array}{l}\text { Produtos e preparados quí- } \\
\text { micos diversos }\end{array}$ & 0,0072 & 0,0060 & 0,0052 & 0,0055 & 0,0059 & 0,0059 & 0,0008 \\
\hline $\begin{array}{l}\text { Outros equipamentos de } \\
\text { transporte }\end{array}$ & 0,0075 & 0,0088 & 0,0082 & 0,0079 & 0,0109 & 0,0086 & 0,0013 \\
\hline $\begin{array}{l}\text { Máq. para escritório e } \\
\text { equip. de informática }\end{array}$ & 0,0079 & 0,0102 & 0,0095 & 0,0093 & 0,0110 & 0,0096 & 0,0012 \\
\hline $\begin{array}{l}\text { Produtos de madeira - ex- } \\
\text { clusive móveis }\end{array}$ & 0,0080 & 0,0074 & 0,0073 & 0,0075 & 0,0081 & 0,0077 & 0,0004 \\
\hline $\begin{array}{l}\text { Metalurgia de metais não- } \\
\text { ferrosos }\end{array}$ & 0,0085 & 0,0105 & 0,0099 & 0,0090 & 0,0070 & 0,0096 & 0,0008 \\
\hline Caminhões e ônibus & 0,0086 & 0,0070 & 0,0068 & 0,0091 & 0,0103 & 0,0084 & 0,0015 \\
\hline $\begin{array}{l}\text { Artefatos de couro e calça- } \\
\text { dos }\end{array}$ & 0,0109 & 0,0095 & 0,0099 & 0,0098 & 0,0095 & 0,0099 & 0,0006 \\
\hline $\begin{array}{l}\text { Perfumaria, higiene e lim- } \\
\text { peza }\end{array}$ & 0,0114 & 0,0116 & 0,0114 & 0,0107 & 0,0125 & 0,0115 & 0,0006 \\
\hline
\end{tabular}

Fonte: Elaboração própria. 
Tabela 3: Multiplicador Financeiro Setorial (MFS) por Setor de Atividade Econômica e por ano (continuação)

\begin{tabular}{|c|c|c|c|c|c|c|c|}
\hline $\begin{array}{l}\text { Multiplicador Finan- } \\
\text { ceiro Setorial/ Ano }\end{array}$ & 2005 & 2006 & 2007 & 2008 & 2009 & Média & Desvio \\
\hline $\begin{array}{l}\text { Administração pública e se- } \\
\text { guridade social }\end{array}$ & 0,0114 & 0,0115 & 0,0126 & 0,0121 & 0,0106 & 0,0116 & 0,0008 \\
\hline $\begin{array}{l}\text { Fabricação de resina e } \\
\text { elastômeros }\end{array}$ & 0,0121 & 0,0116 & 0,0109 & 0,0104 & 0,0082 & 0,0107 & 0,0015 \\
\hline $\begin{array}{l}\text { Outros produtos de mine- } \\
\text { rais não-metálicos }\end{array}$ & 0,0136 & 0,0144 & 0,0130 & 0,0142 & 0,0184 & 0,0147 & 0,0021 \\
\hline Produtos farmacêuticos & 0,0147 & 0,0144 & 0,0132 & 0,0128 & 0,0142 & 0,0139 & 0,0008 \\
\hline Serviços domésticos & 0,0155 & 0,0157 & 0,0152 & 0,0147 & 0,0179 & 0,0158 & 0,0012 \\
\hline $\begin{array}{l}\text { Máquinas, aparelhos e ma- } \\
\text { teriais elétricos }\end{array}$ & 0,0168 & 0,0170 & 0,0163 & 0,0177 & 0,0200 & 0,0176 & 0,0014 \\
\hline $\begin{array}{l}\text { Material eletrônico e equip. } \\
\text { de comunicações }\end{array}$ & 0,0195 & 0,0173 & 0,0148 & 0,0121 & 0,0132 & 0,0154 & 0,0030 \\
\hline Têxteis & 0,0201 & 0,0191 & 0,0184 & 0,0176 & 0,0177 & 0,0186 & 0,0010 \\
\hline $\begin{array}{l}\text { Artigos do vestuário e aces- } \\
\text { sórios }\end{array}$ & 0,0202 & 0,0187 & 0,0196 & 0,0194 & 0,0204 & 0,0197 & 0,0007 \\
\hline $\begin{array}{l}\text { Serviços de manuten- } \\
\text { ção e reparação }\end{array}$ & 0,0215 & 0,0222 & 0,0216 & 0,0225 & 0,0240 & 0,0223 & 0,0010 \\
\hline $\begin{array}{l}\text { Peças e acessórios } \\
\text { para veículos automo- } \\
\text { tores }\end{array}$ & 0,0256 & 0,0231 & 0,0240 & 0,0248 & 0,0270 & 0,0249 & 0,0015 \\
\hline $\begin{array}{l}\text { Celulose e produtos } \\
\text { de papel }\end{array}$ & 0,0259 & 0,0243 & 0,0237 & 0,0228 & 0,0212 & 0,0236 & 0,0017 \\
\hline $\begin{array}{l}\text { Fabricação de aço e de- } \\
\text { rivados }\end{array}$ & 0,0261 & 0,0231 & 0,0252 & 0,0284 & 0,0239 & 0,0253 & 0,0021 \\
\hline Educação mercantil & 0,0266 & 0,0278 & 0,0254 & 0,0234 & 0,0251 & 0,0257 & 0,0016 \\
\hline $\begin{array}{l}\text { Produtos de metal - } \\
\text { exclusive máq. } \\
\text { equip. }\end{array}$ & 0,0273 & 0,0233 & 0,0244 & 0,0249 & 0,0285 & 0,0257 & 0,0022 \\
\hline $\begin{array}{l}\text { Artigos de borracha e } \\
\text { plástico }\end{array}$ & 0,0274 & 0,0259 & 0,0245 & 0,0247 & 0,0271 & 0,0259 & 0,0013 \\
\hline $\begin{array}{l}\text { Móveis e produtos das } \\
\text { indústrias diversas }\end{array}$ & 0,0278 & 0,0246 & 0,0233 & 0,0241 & 0,0260 & 0,0252 & 0,0017 \\
\hline Produtos químicos & 0,0282 & 0,0238 & 0,0247 & 0,0265 & 0,0224 & 0,0251 & 0,0023 \\
\hline
\end{tabular}

Fonte: Elaboração própria. 
Tabela 3: Multiplicador Financeiro Setorial (MFS) por Setor de Atividade Econômica e por ano (continuação)

\begin{tabular}{|c|c|c|c|c|c|c|c|}
\hline $\begin{array}{l}\text { Multiplicador Finan- } \\
\text { ceiro Setorial/ Ano }\end{array}$ & 2005 & 2006 & 2007 & 2008 & 2009 & Média & Desvio \\
\hline $\begin{array}{l}\text { Automóveis, camione- } \\
\text { tas e utilitários }\end{array}$ & 0,0287 & 0,0305 & 0,0342 & 0,0347 & 0,0417 & 0,0339 & 0,0050 \\
\hline $\begin{array}{l}\text { Máquinas e equip., in- } \\
\text { clusive manutenção e } \\
\text { reparos }\end{array}$ & 0,0297 & 0,0298 & 0,0316 & 0,0333 & 0,0383 & 0,0325 & 0,0036 \\
\hline Petróleo e gás natural & 0,0347 & 0,0359 & 0,0287 & 0,0327 & 0,0271 & 0,0318 & 0,0038 \\
\hline Saúde mercantil & 0,0388 & 0,0389 & 0,0387 & 0,0368 & 0,0405 & 0,0388 & 0,0013 \\
\hline Pecuária e pesca & 0,0400 & 0,0358 & 0,0358 & 0,0382 & 0,0404 & 0,0380 & 0,0022 \\
\hline $\begin{array}{l}\text { Jornais, revistas, dis- } \\
\text { cos }\end{array}$ & 0,0402 & 0,0359 & 0,0336 & 0,0343 & 0,0322 & 0,0352 & 0,0031 \\
\hline $\begin{array}{l}\text { Serviços de aloja- } \\
\text { mento e alimentação }\end{array}$ & 0,0426 & 0,0458 & 0,0474 & 0,0456 & 0,0537 & 0,0470 & 0,0041 \\
\hline $\begin{array}{l}\text { Agricultura, silvicul- } \\
\text { tura, exploração flo- } \\
\text { restal }\end{array}$ & 0,0605 & 0,0561 & 0,0573 & 0,0625 & 0,0608 & 0,0595 & 0,0027 \\
\hline $\begin{array}{l}\text { Serviços prestados às } \\
\text { famílias e associativas }\end{array}$ & 0,0620 & 0,0601 & 0,0555 & 0,0545 & 0,0606 & 0,0585 & 0,0033 \\
\hline $\begin{array}{l}\text { Refino de petróleo e } \\
\text { coque }\end{array}$ & 0,0681 & 0,0663 & 0,0610 & 0,0587 & 0,0628 & 0,0634 & 0,0038 \\
\hline $\begin{array}{l}\text { Eletricidade e } \text { gás, } \\
\text { água, esgoto e lim- } \\
\text { peza urbana }\end{array}$ & 0,0854 & 0,0826 & 0,0765 & 0,0746 & 0,0782 & 0,0795 & 0,0045 \\
\hline Construção & 0,1092 & 0,1036 & 0,0940 & 0,0926 & 0,1479 & 0,1095 & 0,0226 \\
\hline $\begin{array}{l}\text { Transporte, armazena- } \\
\text { gem e correio }\end{array}$ & 0,1149 & 0,1107 & 0,1086 & 0,1153 & 0,1249 & 0,1149 & 0,0063 \\
\hline $\begin{array}{l}\text { Serviços imobiliários } \\
\text { e aluguel }\end{array}$ & 0,1205 & 0,1149 & 0,1127 & 0,1078 & 0,1208 & 0,1153 & 0,0055 \\
\hline $\begin{array}{l}\text { Serviços prestados às } \\
\text { empresas }\end{array}$ & 0,1346 & 0,1356 & 0,1306 & 0,1429 & 0,1540 & 0,1395 & 0,0092 \\
\hline Alimentos e Bebidas & 0,1368 & 0,1279 & 0,1264 & 0,1303 & 0,1368 & 0,1316 & 0,0049 \\
\hline $\begin{array}{l}\text { Serviços de informa- } \\
\text { ção }\end{array}$ & 0,1430 & 0,1519 & 0,1454 & 0,1520 & 0,1505 & 0,1486 & 0,0041 \\
\hline Comércio & 0,1771 & 0,1793 & 0,1855 & 0,1896 & 0,2216 & 0,1906 & 0,0180 \\
\hline Soma & 3,2067 & 3,1702 & 3,1239 & 3,1670 & 3,3604 & 3,2056 & 0,1596 \\
\hline
\end{tabular}

Fonte: Elaboração própria. 


\subsection{Análise Fatorial}

A exemplo de Titman \& Wessels (1988), a opção de realizar as estimações usando os fatores oriundos da análise fatorial e não as variáveis originais decorre de as teorias de estrutura de capital trabalharem com constructos teóricos não observados (fatores latentes), tais como tamanho, singularidade e volatilidade, ao invés de métricas objetivas, como ativo total, despesas com vendas, desvio padrão de receitas, etc. Alguns trabalhos usam tais métricas como proxies imperfeitas dos constructos teóricos. Nosso objetivo, entretanto, foi justamente testar a inclusão de todas as variáveis já utilizadas como proxies na obtenção de fatores mais robustos, ao invés de escolher, de forma ad hoc, uma das métricas como proxy de um constructo complexo. Um exemplo emblemático é a utilização da métrica 'depreciação' como proxy para o fator 'outros benefícios fiscais', comumente vista em trabalhos empíricos sobre o tema. A técnica de análise fatorial revela que essa proxy é muito correlacionada ao estoque de ativos fixos da firma. Portanto, a variável pode ser tanto uma proxy para o constructo 'outros benefícios fiscais' quanto para 'tangibilidade'. A técnica de análise fatorial permite dizer a que constructo (fator latente) ela mais se relaciona. A técnica ainda permite que todas as variáveis encontradas na revisão de estrutura de capital sejam consideradas na estimação, evitando problemas com multicolinearidade dado que os fatores encontrados são ortogonais entre si.

O método de extração foi o de componentes principais, no qual os primeiros fatores possuem maior número de variáveis relevantes. Os fatores foram rotacionados pelo método Varimax, rotação ortogonal, com o objetivo de melhor identificar os principais componentes de cada fator (que serão nomeados conforme os constructos teóricos encontrados na literatura).

Como se trata de uma análise exploratória, o número de fatores latentes é desconhecido, bem como o que eles representam (Hair 1998). Neste trabalho, são considerados fatores com autovalores maiores que 1. Após a formação dos fatores, foram analisadas as variáveis originais com maiores escores em cada fator, para nomeá-los a partir de seus componentes. Ao final do processo, 9 fatores foram considerados.

Antes da realização da análise fatorial, os valores faltantes (missings) foram substituídos pela média da variável no período (2005-2009), para permitir a inversão da matriz de variáveis (operação necessária à estimação da análise fatorial $)^{8}$. Considerando o curto período de tempo e a inércia de indicadores contábeis, a adequação da análise fatorial foi verificada pela medida KMO (Kaiser-Meyer-Olkin), de 0,61.

A Tabela 4 apresenta os pesos identificados para cada variável original em relação aos fatores criados.

Os fatores relacionados aos constructos teóricos foram denominados de acordo com as variáveis originais que os compõem:

- Fator 1 (F1_Fcf): é formado pelas três variáveis de margem (Margem de Lucro Líquido, Margem de Lucro Operacional e Margem Ebitda), além da variável de benefícios fiscais decorrentes da dívida. Foi denominado 'fluxo livre de caixa'.

\footnotetext{
${ }^{8}$ Como teste de robustez, foi feita a análise fatorial sem a substituição dos missings pelas médias do período. Entretanto, o resultado apresentou fatores formados exclusivamente por variáveis missings, como se esta fosse uma "característica" da empresa, enviesando a análise.
} 
Tabela 4: Matriz de Componentes dos Fatores Rotacionados

\begin{tabular}{|c|c|c|c|c|c|c|c|c|c|}
\hline & \multicolumn{9}{|c|}{ Componentes } \\
\hline & 1 & 2 & 3 & 4 & 5 & 6 & 7 & 8 & 9 \\
\hline MARG & 0,983 & & & & & & & & \\
\hline FISC & 0,983 & & & & & & & & \\
\hline MGOP & 0,972 & & & & & & & & \\
\hline MGEBITDA & 0,481 & & & & & & & & \\
\hline \multicolumn{10}{|l|}{ SALES_REV } \\
\hline LNTA & & 0,835 & 0,301 & & & & & & \\
\hline LNREV & & 0,764 & & & & & & & \\
\hline LNE & & 0,721 & & & & & & & \\
\hline \multicolumn{10}{|l|}{$\overline{\text { SEG_N2 }}$} \\
\hline LIQB & & & 0,833 & & & & & & \\
\hline VOLNEG & & & 0,803 & & & & & & \\
\hline IBOV & & 0,413 & 0,526 & & & & & & \\
\hline SEG_N1 & & & 0,49 & & & & & & \\
\hline S_MS & & & 0,474 & & & & & & \\
\hline \multicolumn{10}{|l|}{ VARTA } \\
\hline NTAX & & & & 0,963 & & & & & \\
\hline TURN & & & & 0,959 & & & & & \\
\hline TANG & & & & 0,498 & $-0,365$ & & & & \\
\hline ROAOP & & & & & 0,974 & & & & \\
\hline$\overline{R O A}$ & & & & & 0,962 & & & & \\
\hline VARREV & & & & & $-0,313$ & & & & \\
\hline CONC2 & & & & & & 0,951 & & & \\
\hline CONC1 & & & & & & 0,945 & & & \\
\hline RISKFREE & & & & & & & $\begin{array}{l}-0,804 \\
\end{array}$ & & \\
\hline VARBONDS & & & & & & & 0,657 & & \\
\hline SEG_NM & & 0,313 & & & & & 0,475 & & \\
\hline DISP & & & & & & & 0,387 & & \\
\hline \multicolumn{10}{|l|}{ VARE_REV } \\
\hline SDOP & & & & & & & & 0,643 & \\
\hline SDEBITDA & & & & & & & & 0,616 & \\
\hline QUALD & & & & & & & & $-0,545$ & \\
\hline \multicolumn{10}{|l|}{ DISTRIB } \\
\hline \multicolumn{10}{|l|}{ LIQA } \\
\hline EXPOL & & & & & & & & & 0,792 \\
\hline RETIBOV & & & & & & & $-0,379$ & & 0,747 \\
\hline RETSTOCK & & & & & & & & & 0,361 \\
\hline \multicolumn{10}{|l|}{ MTB } \\
\hline \multicolumn{10}{|l|}{ KD } \\
\hline \multicolumn{10}{|l|}{ AGE } \\
\hline IPOAGE & & & & & & & & & \\
\hline
\end{tabular}

Fonte: Elaboração própria. 
- Fator 2 (F2_Size): tem como principais componentes as projeções das três proxies de tamanho (Ativo, Patrimônio Líquido e Receita), além das dummies de participação no índice Bovespa (IBOV) e no segmento de Novo Mercado da B3. Foi denominado 'tamanho' ou 'porte'.

- Fator 3 (F3_Bluechipness): com as variáveis de liquidez em bolsa e volume de negócios no mercado, o valor do fator é maior para empresastempo com maior liquidez de negociações. Além disso, apresenta também componentes positivos para a proxy de tamanho e a variável de market share (S_MS), representando empresas mais consolidadas no mercado. Por fim, as dummies de participação no IBOV e no segmento de mercado N1 também são representativas. No caso da participação no IBOV, é natural que ele contemple empresas maduras e amplamente negociadas. É interessante notar a participação no segmento de mercado $\mathrm{N} 1$, que é o segmento de maior grau de transparência na Bolsa, sem perda de controle (empresas maduras não teriam incentivos a buscar os maiores níveis de diluição de controle do Novo Mercado, justamente por já serem consolidadas e possuírem alta liquidez de mercado). Dadas as características do mercado acionário no Brasil, esse está relacionado à atratividade da empresa no mercado secundário, tendo sido denominado bluechipness.

- Fator 4 (F4_Tang): apresenta componentes positivos de benefícios fiscais não provenientes da dívida (depreciações e amortizações), giro e tangibilidade dos ativos. A maior proporção de ativos tangíveis é responsável por uma maior taxa de depreciação, sendo esta relação positiva. A variável de giro, entretanto, apresenta o ativo total como denominador, assim as empresas cujo ativo é maior (e provavelmente também o ativo imobilizado), deveriam apresentar menor turnover. Entretanto, o que se observa é que empresas com maior imobilizado giram mais (relação positiva), provavelmente em função de maiores receitas auferidas (numerador do giro) e não em função do aumento do ativo total (denominador do giro). De fato, foi observado que as receitas das empresas crescem mais que proporcionalmente à variação do ativo imobilizado na amostra. Dadas tais características, esse fator foi denominado 'tangibilidade';

- Fator 5 (F5_Profit): apresenta componentes positivos para as variáveis de lucros sobre os ativos totais, medidas tanto pelo lucro operacional (ROAOP) quanto pelo lucro líquido (ROA), indicando ser uma proxy de rentabilidade. O componente negativo de variação percentual das receitas operacionais (VARREV) indica que empresas com receitas mais voláteis são menos rentáveis. O componente negativo da tangibilidade dos ativos, por sua vez, indica que as empresas com maior lucratividade são aquelas capazes de gerar altos retornos por unidade de ativos fixos. O fator foi denominado 'lucratividade';

- Fator 6 (F6_Stconc): tem como componentes as duas variáveis de estrutura de concentração de propriedade das empresas, configurando-se uma proxy de (baixa) governança corporativa a partir desse critério. Foi denominado 'estrutura de concentração';

- Fator 7 (F7_Hotmktdebt): apresenta um componente negativo (RISKFREE) da taxa Selic (taxas de empréstimos mais baixas), além da varia- 
ção positiva de emissão de debêntures, associada a um retorno negativo do índice Bovespa, sinais que apontam para um hot market de emissão de dívida. Além disso, a presença dos componentes de participação no segmento de Novo Mercado e de maiores disponibilidades de recursos indicam que o fator não considera apenas as questões mercadológicas, mas também as empresas em melhores condições de se beneficiar da janela de oportunidade que se apresenta. Foi denominado 'hot market de dívida';

- Fator 8 (F8_Risk): é representado pela alta variabilidade dos retornos da empresa, dada pelos desvios padrões dos lucros operacionais e EBITDA, além do componente de qualidade da dívida com sinal negativo. Tratase, portanto, de proxy de "risco operacional";

- Fator 9 (F9_Hotmktstock): os componentes positivos de política governamental expansionista (o que implica numa expectativa maior de crescimento das firmas) e dos retornos maiores tanto do índice Bovespa quanto da ação da própria empresa apontam para um "hot market de emissão de ações".

Algumas variáveis, entretanto, não foram incorporadas a nenhum fator. Entre elas, as proxies para oportunidades de crescimento $\left(\mathrm{VARTA}_{i t}\right.$ e $\mathrm{MTB}_{i t}$ ), importantes para medir questões de agência e de ciclo de vida; qualidade da governança $\left(\right.$ SEG_N2 ${ }_{i t}$ ), singularidade (SALES_REV $i t$ ), distribuição (DISTRIB ${ }_{i t}$ e VARE_REV $\left.{ }_{i t}\right)$, liquidez contábil $\left(\mathrm{LIQA}_{i t}\right)$, custo da dívida $\left(\mathrm{KD}_{i t}\right)$ e idade das firmas $\left(\mathrm{AGE}_{i t}\right.$ e IPOAGE $\left.\mathrm{A}_{i t}\right)$. Essas variáveis, assim como as variáveis setoriais, foram então consideradas isoladamente nas regressões (embora como será visto, somente o custo da dívida, foi significativo).

\subsection{Dynamic Trade-Off}

A variação no nível de endividamento da empresa é função de sua dinâmica rumo ao nível de endividamento meta. O modelo de ajuste parcial proposto por Flannery \& Rangan (2006) é dado pela equação (2):

$$
D_{i, t}-D_{i, t-1}=\gamma\left(D_{i, t}^{*}-D_{i, t-1}\right)+e_{i, t}
$$

onde:

$D_{i, t}=$ endividamento da firma $i$, no período atual $(t)$;

$D_{i, t-1}=$ endividamento da firma $i$ no período anterior $(t-1)$;

$D_{i, t}^{*}=$ meta de endividamento da firma $i$ no período atual $(t)$.

A cada período, as empresas alcançam uma proporção $\gamma$ do gap entre seu nível atual e o nível desejado de endividamento. Portanto, a dinâmica do ajustamento pode ser capturada por $\gamma$. Se $\gamma=1$, o ajuste é perfeito e imediato. Se $\gamma<1$, há custos de ajustamento e a empresa não altera seu nível de endividamento em busca do ótimo de forma completa (Flannery \& Rangan 2006).

O endividamento meta $\left(D_{i, t}^{*}\right)$ é não observável, mas, com base nas teorias de Trade-Off, a estrutura meta guarda uma relação composta por diversas características das empresas, assimetrias, relacionamentos de agência, características do setor, de governança, entre outros, capazes de gerar custos e benefícios ao endividamento. Essa relação é expressa pela equação (3): 


$$
D_{i, t+1}^{*}=\beta X_{i, t}+u_{i, t}
$$

onde $D_{i, t+1}^{*}$ é o endividamento meta no período seguinte e $X_{i, t}$ é o vetor de características relacionadas aos custos e benefícios de estar operando em determinado nível de endividamento.

Substituindo (3) em (2) e reorganizando, tem-se um modelo passível de ser estimado em uma única expressão, apresentada na equação (4):

$$
D_{i, t}=(\gamma \beta) X_{i, t-1}+(1-\gamma) D_{i, t-1}+\epsilon_{i t}
$$

Obtendo-se o valor de $(1-\gamma)$, pode-se calcular o grau de ajustamento em relação à meta de endividamento $(\gamma)$.

O modelo foi estimado pelo Método de Variáveis Instrumentais (Instrumental Variables - IV) em primeira diferença (First Diference - FD). Como destacam Anderson \& Hsiao (1982), no modelo em diferenças, instrumentalizando a variável dependente defasada com a sua segunda diferença (variável segunda defasagem $=\Delta D_{i, t-2}=D_{i, t-2}-D_{i, t-3}$ ), ao tratar os dados em primeira diferença, elimina-se o efeito fixo; ao instrumentalizar a variável dependente defasada, com instrumento adequado, obtêm-se estimadores consistentes mesmo na presença de endogeneidade.

O instrumento proposto, a segunda diferença da variável defasada, apresentase adequado, pois há correlação elevada com variável original e, por construção, é não correlacionado com o erro. Fatores não observáveis que influenciam simultaneamente o endividamento atual e as demais variáveis exógenas contemporâneas (o termo de erro), não podem influenciar variáveis cujos valores foram definidos no passado, como a segunda diferença do endividamento defasado.

Foram ainda inseridas dummies trimestrais para controlar o efeito de choques macroeconômicos e evitar o enviesamento do estimador de erro padrão em função de correlação dos erros, e utilizada a correção de erros agrupados por empresa para o cálculo do erro padrão (clustered standard errors no nível da empresa), evitando distorções do erro padrão e da estatística $t$ em razão de heterocedasticidade e autocorrelação dos erros do modelo.

Para inserir o Multiplicador Financeiro Setorial (MFS), que é anual, no modelo com variáveis observadas trimestralmente, foi criada uma variável de interação entre o endividamento da firma $i$ no tempo $t$ e o MFS do setor $j$ a que a firma pertence no tempo $t\left(\mathrm{MFS}_{j t} \times \mathrm{D}_{i t}\right)$.

Estratégia semelhante foi adotada por Cook \& Tang (2010) para avaliar o efeito de variáveis macroeconômicas no grau de ajustamento da estrutura de capital e por Zappa (2011) para avaliar o efeito da Governança Corporativa no grau de ajustamento.

Tal variável de interação, inserida no modelo defasada em um período, representa a sensibilidade da empresa $i$, dado seu estoque de financiamento $\mathrm{D}$, ao fluxo de fundos ao setor $j$ provido pelo setor financeiro (MFS).

De modo a avaliar os efeitos separados do endividamento em $t-1$ e do MSF, os modelos foram estimados primeiro apenas com a variável dependente defasada e, posteriormente, com ela e a variável de interação.

A primeira estimação irá fornecer o grau de ajustamento da estrutura de capital das empresas brasileiras sem considerar a sensibilidade setorial. Este será o parâmetro utilizado para verificar o grau de ajustamento da estrutura 
de capital setorial, considerando o MFS interagindo com o endividamento defasado.

Inicialmente, a matriz de variáveis foi composta por constructos teóricos representados pelos 9 fatores latentes encontrados via Análise Fatorial, mais 9 variáveis individuais, mais as 8 variáveis setoriais, incluindo a variável de interação entre o MFS e endividamento. As variáveis explicativas foram consideradas na sua primeira defasagem.

Posteriormente, por stepwise foram sendo excluídas as variáveis que não apresentavam significância (estatística $t$ ) no modelo estimado pelo Método de Variáveis Instrumentais em primeiras diferenças.

Dentre os fatores, dois não se mostraram significativos (indicadores de tamanho, f3-SIZE e indicadores de concentração de propriedade, f6-CONC). Dentre as variáveis a nível da firma, apenas uma se apresentou significativa $\left(\right.$ Custo $\left.=\mathrm{KD}_{i t}\right)$ e dentre as variáveis setoriais apenas uma se apresentou significativa (Alavancagem Setorial $=$ ALAVSET $_{i t}$ ).

Além da variável endividamento defasada, instrumentalizada pela segunda diferença, e a variável de interação entre o MFS e endividamento, o modelo final contou com 9 variáveis explicativas, sendo 7 fatores, 1 variável em nível da firma e 1 variável em nível de setor. As estatísticas descritivas das variáveis explicativas mantidas no modelo, são apresentadas na Tabela 5.

Tabela 5: Estatísticas descritivas das variáveis explicativas

\begin{tabular}{l|c|c|c|c|c}
\hline Variável Explicativa & N. Obs & Média & Desvio Padrão & Min & Máx \\
\hline $\mathrm{D}_{t-1}$ & 7088 & 2,25 & 15,71 & 0,00 & 427,82 \\
F1_Fcf & 7095 & $-0,005$ & 1,26 & $-54,85$ & 14,76 \\
F3_Bluechipness & 7095 & $-0,02$ & 1,03 & $-2,85$ & 15,37 \\
F4_Tang & 7095 & 0,001 & 0,20 & $-0,20$ & 11,98 \\
F5_Profit & 7095 & $-0,01$ & 1,25 & $-100,24$ & 9,42 \\
F7_Hotmktdebt & 7095 & $-0,06$ & 0,58 & $-1,77$ & 2,94 \\
F8_Risk & 7095 & $-0,11$ & 0,95 & $-3,27$ & 3,83 \\
F9_Hotmktstock & 7095 & 0,33 & 1,09 & $-2,19$ & 11,11 \\
KD & 6936 & 1,92 & 94,66 & $-2,60$ & $6.360,25$ \\
ALAVSET & 7095 & 2,26 & 4,42 & 0,00 & 40,13 \\
MSF $_{t-1}{ }^{*} \mathrm{D}_{t-1}$ & 7088 & 0,15 & 1,44 & 0,00 & 48,58 \\
\hline
\end{tabular}

Fonte: Elaboração própria.

\section{Resultados}

O resultado da estimação do modelo de DTO é apresentado na Tabela 6, com e sem a consideração do MFS. O grau de ajustamento das empresas brasileiras em direção à estrutura ótima é positivo, significativo e está entre 0 e 1 em todas as modelagens, indicando que há custos de ajustamento, pois as empresas da amostra não alteraram seu nível de endividamento em busca do ótimo de forma completa 9

\footnotetext{
${ }^{9}$ Foram realizados dois testes de robustez, nos quais o sinal do MSF se manteve: (1) estimação com dados anuais, inserindo o MSF sem interação nas regressões e (2) estimação considerando como variável independente apenas o endividamento em $\mathrm{t}-1 \mathrm{e}$, posteriormente, inserindo a variável interagindo com o MSF. Nesse segundo teste, a diferença entre os coeficientes da variável 'endividamento em t-1' nas 2 estimações reflete o efeito do multiplicador sobre o padrão de endi-
} 
Tabela 6: Estimação do modelo de Dinamic Trade-Off. A variável dependente é o endividamento por unidade de ativo total,. As variáveis independentes estão em primeira defasagem. Foram inseridas dummies trimestrais e correção para heterocedasticidade. Nas estimações realizadas por Variáveis Instrumentais em Primeira Diferença (IV FD), o instrumento é a segunda defasagem da variável dependente. São apresentadas as estimações com e sem o Multiplicador Financeiro Setorial interagindo com endividamento defasado $\left(\mathrm{MFS}_{t-1} \times \mathrm{D}_{t-1}\right)$. A estatística $t$ é apresentada entre parênteses abaixo do coeficiente estimado, sinalizada com a indicação do nível de significância, sendo * a $10 \%,{ }^{* *}$ a $5 \%$ e *** $1 \%$.

\begin{tabular}{|c|c|c|}
\hline Dt & IV FD sem MFS & IV FD com MFS \\
\hline $\mathrm{D}_{t-1}$ & $\begin{array}{l}0,32^{*} \\
(2,27)\end{array}$ & $\begin{array}{c}0,77^{* *} \\
(2,77)\end{array}$ \\
\hline $\mathrm{F} 1 \_\mathrm{Fcf}_{t-1}$ & $\begin{array}{l}\frac{\left(2,50^{* * *}\right.}{0,69)} \\
(3,69)\end{array}$ & $\begin{array}{l}0,81^{* * *} \\
(3,76)\end{array}$ \\
\hline F3_Bluechipness $t-1$ & $\begin{array}{l}1,69^{* * *} \\
(5,76)\end{array}$ & $\begin{array}{l}2,12^{* * *} \\
(5,40)\end{array}$ \\
\hline $\mathrm{F} 4 \_\operatorname{Tang}_{t-1}$ & $\begin{array}{l}-28,59^{* * *} \\
(-6,88)\end{array}$ & $\begin{array}{l}-37,33^{* * *} \\
(-5,53)\end{array}$ \\
\hline $\mathrm{F}_{-}$Profit ${ }_{t-1}$ & $\begin{array}{c}-40,16^{* * *} \\
(-7,16)\end{array}$ & $\begin{array}{c}-50,98^{* * *} \\
(-5,97)\end{array}$ \\
\hline F7_Hotmktdebt $t_{t-1}$ & $\begin{array}{l}4,06^{* * *} \\
(7,72)\end{array}$ & $\begin{array}{l}4,83^{* * *} \\
(6,85)\end{array}$ \\
\hline F8_Risk ${ }_{t-1}$ & $\begin{array}{l}-1,51^{* * *} \\
(-6,69)\end{array}$ & $\begin{array}{l}-1,88^{* * *} \\
(-5,92)\end{array}$ \\
\hline F9_Hotmktstock $t_{t-1}$ & $\begin{array}{c}0,28 \\
(1,44)\end{array}$ & $\begin{array}{c}0,52^{*} \\
(2,15)\end{array}$ \\
\hline $\mathrm{KD}_{t-1}$ & $\begin{array}{l}0,01^{* * *} \\
(6,42)\end{array}$ & $\begin{array}{l}0,01^{* * *} \\
(5,39)\end{array}$ \\
\hline ALAVSET $_{t-1}$ & $\begin{array}{l}0,14^{*} \\
(2,57)\end{array}$ & $\begin{array}{r}0,09 \\
(1,38)\end{array}$ \\
\hline$\left(\mathrm{MSF}_{t-1}{ }^{\star} \mathrm{D}_{t-1}\right)$ & - & $\begin{array}{c}-4,71^{* *} \\
(-3,39)\end{array}$ \\
\hline Constante & $\begin{array}{l}-0,11 \\
(-1,48)\end{array}$ & $\begin{array}{l}-0,18^{*} \\
(-2,07)\end{array}$ \\
\hline R2 & 0,79 & 0,82 \\
\hline $\mathrm{N}^{\circ}$ de Observações & 5632 & 5632 \\
\hline$N^{o}$ de Grupos & 405 & 405 \\
\hline No de Períodos & 17 & 17 \\
\hline $\begin{array}{l}\text { Grau Ajust. } \\
\text { Estrutura Ótima }(\gamma=1-b)\end{array}$ & 0,68 & 0,23 \\
\hline
\end{tabular}

Fonte: Elaboração própria. 
Os fatores determinantes do endividamento se apresentaram significativos no modelo, indicando que as empresas aumentam o estoque de dívida em momentos de hot market no mercado de dívidas (Fator 7 positivamente correlacionado ao nível de endividamento), reforçando a hipótese de Market Timing, e que são mais endividadas as empresas em fase de maturidade (alta geração de fluxo de caixa, baixo risco e bluechips), confirmando hipóteses subjacentes à DTO.

A significância do Fator 1 (Fluxo de caixa livre) é convergente com a existência de problemas de agência do capital próprio, em que a dívida é utilizada para limitar o poder de expropriação da riqueza do acionista, mas também com a hipótese de complementaridade entre recursos internos e externos, proposta por Almeida \& Campelo (2007). Importante lembrar que, no Brasil, um dos covenants mais utilizados para garantia da dívida é a razão despesas financeiras em relação ao fluxo de caixa operacional. Portanto, o aumento desse indicador reduz a restrição financeira das firmas.

Quanto ao Fator 3 ("Bluechipness"), a relação positiva observada corrobora a predição de que empresas mais bem avaliadas pelo mercado (menor assimetria) têm mais facilidade em obter recursos externos. O Fator 8 (Risco) negativamente relacionado ao endividamento também fortalece as predições da teoria de DTO, visto que maior risco implica em maiores custos para incrementos no nível de alavancagem.

O Fator 4 (Tangibilidade) se mostrou negativamente relacionado com o endividamento. Este comportamento pode ser explicado pela forte participação da variável de benefícios fiscais não decorrentes da dívida no fator (como depreciação, que é bastante correlacionada ao nível de ativos tangíveis). Conforme a DTO, empresas com mais benefícios fiscais não decorrentes da dívida teriam tendência em manter menores níveis de endividamento por obterem menos benefícios fiscais com seu uso. Oliveira et al. (2012) e Correa et al. (2013) também encontram relação negativa entre tangibilidade e endividamento para empresas brasileiras.

Também a variável de turnover (giro do ativo) tem forte presença no fator, sendo um dos componentes da lucratividade da firma e corroborando a relação negativa encontrada para o Fator 5 (Lucratividade). Nesse fator, encontram-se dois componentes de rentabilidade: o retorno operacional e o retorno do ativo. O resultado converge com a proposta da POT sem restrição. Resultado na mesma direção é observado em Perobelli \& Fama (2003).

Dentre as variáveis individuais que não se alinharam aos fatores, somente o custo da dívida (KD), se demonstrou significativo, positivamente relacionado ao nível de endividamento. Esses dois resultados (lucratividade e custo) indicam que empresas que não têm acesso a lucros acumulados fazem uso de endividamento para honrar suas obrigações sempre que possível, reforçando a hipótese original da POT.

A Tabela 7 resume o sinal encontrado na estimação para cada variável significativa e apresenta a teoria à qual o sinal se relaciona.

No modelo que não considera o MFS, o coeficiente estimado para a variável dependente defasada é 0,32 , indicando um grau de ajustamento de $68 \%$ ao período, já no modelo que inclui o MFS interagindo com o endividamento, o coeficiente estimado para a variável defasada é 0,77 indicando um grau de

vidamento. No primeiro teste, a redução das unidades observacionais impediu a estimação por Variáveis Instrumentais em Primeira Diferença. 
Tabela 7: Sinal estimado e teoria relacionada.

\begin{tabular}{l|c|c}
\hline Fatores/Variáveis & Sinal Observado & Teoria Correspondente \\
\hline F1- Fluxo de caixa & + & DTO, PTO com restrição financeira \\
F3 - Bluechips & + & DTO \\
F4 - Tangibilidade & - & DTO \\
F5 - Lucratividade & - & POT original \\
F7 - Hot market dívidas & + & Market Timing \\
F8 - Risco & - & DTO \\
F9 - Hot market ações & + & Market Timing \\
KD & + & POT \\
Alavanc. Setorial & + & DTO \\
MFS & - & Restrição financeira \\
\hline
\end{tabular}

Fonte: Elaboração própria.

ajustamento de $23 \%$ ao período. Logo, a inclusão do indicador de sensibilidade aumenta a importância do coeficiente do estoque de dívida sobre o endividamento atual, gerando menor velocidade de ajustamento em direção a um novo nível de endividamento. Dessa forma a sensibilidade setorial pode ser considerada uma medida de restrição financeira.

No modelo que inclui o MFS, observa-se ainda que a variável alavancagem setorial não se apresenta significativa podendo indicar que o MFS exprime os efeitos das características setoriais.

O coeficiente estimado para a variável de interação é significativo e negativo, igual a $-4,71$. Considerando a derivada parcial, o coeficiente estimado para o endividamento no período anterior deve ser ajustado conforme expresso pela equação (5):

$$
\beta_{D_{t-1}}=0,77-\left(4,71 \times M F S_{t-1}\right)
$$

Assim, o grau de ajustamento da estrutura de capital, dada a equação (5) pode ser expresso pela equação (6):

$$
\text { Grau de Ajustamento }=1-\left[0,77-\left(4,71 \times M F S_{t-1}\right)\right]
$$

A Tabela 8 apresentam o grau de ajustamento da estrutura de capital das empresas brasileiras por setor de atividade econômica, por ano, e o valor médio dos 5 anos, calculado conforme a equação (6), organizados em ordem crescente de MFS.

Como se pode observar, setores com menor MFS apresentam menores graus de ajustamento da estrutura de capital e setores com maiores MFS apresentam maiores graus de ajustamento da estrutura de capital. Entretanto, considerando a inclusão do MFS na equação de ajustamento, ele aumenta a importância do estoque de dívida e diminui o grau de ajustamento da média das empresas, podendo ser considerado uma medida de restrição.

\section{Considerações Finais}

O objetivo deste trabalho foi avaliar se a sensibilidade setorial a choques exógenos na demanda agregada sobre o setor de intermediação financeira afeta o grau de ajustamento da estrutura de capital de empresas não financeiras brasileiras. 
Tabela 8: Grau de ajustamento da estrutura de capital por setor

\begin{tabular}{|c|c|c|c|c|c|c|}
\hline Setores & 2005 & 2006 & 2007 & 2008 & 2009 & Média \\
\hline Educação pública & 0,23 & 0,23 & 0,23 & 0,23 & 0,23 & 0,23 \\
\hline Saúde pública & 0,24 & 0,23 & 0,23 & 0,23 & 0,23 & 0,23 \\
\hline Minério de ferro & 0,24 & 0,24 & 0,24 & 0,24 & 0,24 & 0,24 \\
\hline Produtos do fumo & 0,25 &, 25 & 0,25 & 0,25 & 0,25 & 0,25 \\
\hline Cimento & 0,25 & 0,25 & 0,25 & 0,25 & 0,26 & 0,25 \\
\hline $\begin{array}{l}\text { Tintas, vernizes, esmaltes e } \\
\text { lacas }\end{array}$ & 0,25 & 0,25 & 0,25 & 0,25 & 0,26 & 0,25 \\
\hline $\begin{array}{l}\text { Outros da indústria extra- } \\
\text { tiva }\end{array}$ & 0,25 & 0,25 & 0,25 & 0,25 & 0,26 & 0,25 \\
\hline Defensivos agrícolas & 0,26 & 0,25 & 0,26 & 0,26 & 0,26 & 0,26 \\
\hline $\begin{array}{l}\text { Produtos e preparados quí- } \\
\text { micos diversos }\end{array}$ & 0,26 & 0,26 & 0,25 & 0,26 & 0,26 & 0,26 \\
\hline Eletrodomésticos & 0,26 & 0,26 & 0,26 & 0,26 & 0,26 & 0,26 \\
\hline $\begin{array}{l}\text { Aparelhos/instrumentos } \\
\text { médico-hospitalar, medida } \\
\text { e óptico }\end{array}$ & 0,26 & 0,26 & 0,26 & 0,26 & 0,26 & 0,26 \\
\hline $\begin{array}{l}\text { Produtos de madeira - ex- } \\
\text { clusive móveis }\end{array}$ & 0,27 & 0,26 & 0,26 & 0,27 & 0,27 & 0,27 \\
\hline Álcool & 0,26 & 0,26 & 0,27 & 0,27 & 0,27 & 0,27 \\
\hline Caminhões e ônibus & 0,27 & 0,26 & 0,26 & 0,27 & 0,28 & 0,27 \\
\hline $\begin{array}{l}\text { Outros equipamentos de } \\
\text { transporte }\end{array}$ & 0,27 & 0,27 & 0,27 & 0,27 & 0,28 & 0,27 \\
\hline $\begin{array}{l}\text { Metalurgia de metais não- } \\
\text { ferrosos }\end{array}$ & 0,27 & 0,28 & 0,28 & 0,27 & 0,28 & 0,28 \\
\hline $\begin{array}{l}\text { Máquinas para escritório e } \\
\text { equipamentos de informá- } \\
\text { tica }\end{array}$ & 0,27 & 0,28 & 0,27 & 0,27 & 0,28 & 0,28 \\
\hline $\begin{array}{l}\text { Artefatos de couro e calça- } \\
\text { dos }\end{array}$ & 0,28 & 0,27 & 0,28 & 0,28 & 0,27 & 0,28 \\
\hline $\begin{array}{llll}\begin{array}{l}\text { Fabricação de } \\
\text { elastômeros }\end{array} & \text { resina } & \text { e } \\
\end{array}$ & 0,29 & 0,28 & 0,28 & 0,28 & 0,27 & 0,28 \\
\hline $\begin{array}{l}\text { Perfumaria, higiene e lim- } \\
\text { peza }\end{array}$ & 0,28 & 0,28 & 0,28 & 0,28 & 0,29 & 0,28 \\
\hline $\begin{array}{l}\text { Administração pública e se- } \\
\text { guridade social }\end{array}$ & 0,28 & 0,28 & 0,29 & 0,29 & 0,28 & 0,28 \\
\hline Produtos farmacêuticos & 0,30 & 0,30 & 0,29 & 0,29 & 0,30 & 0,30 \\
\hline $\begin{array}{l}\text { Outros produtos de mine- } \\
\text { rais não-metálicos }\end{array}$ & 0,29 & 0,30 & 0,29 & 0,30 & 0,32 & 0,30 \\
\hline $\begin{array}{l}\text { Material eletrônico e equi- } \\
\text { pamentos de comunicações }\end{array}$ & 0,32 & 0,31 & 0,30 & 0,29 & 0,29 & 0,30 \\
\hline Serviços domésticos & 0,30 & 0,30 & 0,30 & 0,30 & 0,31 & 0,30 \\
\hline $\begin{array}{l}\text { Máquinas, aparelhos e ma- } \\
\text { teriais elétricos }\end{array}$ & 0,31 & 0,31 & 0,31 & 0,31 & 0,32 & 0,31 \\
\hline Têxteis & 0,32 & 0,32 & 0,32 & 0,31 & 0,31 & 0,32 \\
\hline $\begin{array}{l}\text { Artigos do vestuário e aces- } \\
\text { sórios }\end{array}$ & 0,33 & 0,32 & 0,32 & 0,32 & 0,33 & 0,32 \\
\hline $\begin{array}{l}\text { Serviços de manutenção e } \\
\text { reparação }\end{array}$ & 0,33 & 0,33 & 0,33 & 0,34 & 0,34 & 0,34 \\
\hline
\end{tabular}

Fonte: Elaboração própria. 
Tabela 8: Grau de ajustamento da estrutura de capital por setor (continuação)

\begin{tabular}{|c|c|c|c|c|c|c|}
\hline Setores & 2005 & 2006 & 2007 & 2008 & 2009 & Média \\
\hline $\begin{array}{l}\text { Celulose e produtos de pa- } \\
\text { pel }\end{array}$ & 0,35 & 0,34 & 0,34 & 0,34 & 0,33 & 0,34 \\
\hline $\begin{array}{l}\text { Peças e acessórios para veí- } \\
\text { culos automotores }\end{array}$ & 0,35 & 0,34 & 0,34 & 0,35 & 0,36 & 0,35 \\
\hline Produtos químicos & 0,36 & 0,34 & 0,35 & 0,35 & 0,34 & 0,35 \\
\hline $\begin{array}{l}\text { Móveis e produtos das in- } \\
\text { dústrias diversas }\end{array}$ & 0,36 & 0,35 & 0,34 & 0,34 & 0,35 & 0,35 \\
\hline $\begin{array}{l}\text { Fabricação de aço e deriva- } \\
\text { dos }\end{array}$ & 0,35 & 0,34 & 0,35 & 0,36 & 0,34 & 0,35 \\
\hline Educação mercantil & 0,36 & 0,36 & 0,35 & 0,34 & 0,35 & 0,35 \\
\hline $\begin{array}{l}\text { Produtos de metal - ex- } \\
\text { clusive máquinas e equipa- } \\
\text { mentos }\end{array}$ & 0,36 & 0,34 & 0,34 & 0,35 & 0,36 & 0,35 \\
\hline $\begin{array}{l}\text { Artigos de borracha e plás- } \\
\text { tico }\end{array}$ & 0,36 & 0,35 & 0,35 & 0,35 & 0,36 & 0,35 \\
\hline Petróleo e gás natural & 0,39 & 0,40 & 0,37 & 0,38 & 0,36 & 0,38 \\
\hline $\begin{array}{l}\text { Máquinas e equipamentos, } \\
\text { inclusive manutenção e re- } \\
\text { paros }\end{array}$ & 0,37 & 0,37 & 0,38 & 0,39 & 0,41 & 0,38 \\
\hline $\begin{array}{l}\text { Automóveis, camionetas e } \\
\text { utilitários }\end{array}$ & 0,37 & 0,37 & 0,39 & 0,39 & 0,43 & 0,39 \\
\hline Jornais, revistas, discos & 0,42 & 0,40 & 0,39 & 0,39 & 0,38 & 0,40 \\
\hline Pecuária e pesca & 0,42 & 0,40 & 0,40 & 0,41 & 42 & 0,41 \\
\hline Saúde mercantil & 0,41 & 0,41 & 0,41 & 0,40 & 0,42 & 0,41 \\
\hline $\begin{array}{l}\text { Serviços de alojamento e } \\
\text { alimentação }\end{array}$ & 0,43 & 0,45 & 0,45 & 0,44 & 0,48 & 0,45 \\
\hline $\begin{array}{l}\text { Serviços prestados às famí- } \\
\text { lias e associativas }\end{array}$ & 0,52 & 0,51 & 0,49 & 0,49 & 0,52 & 0,51 \\
\hline $\begin{array}{l}\text { Agricultura, silvicultura, } \\
\text { exploração florestal }\end{array}$ & 0,52 & 0,49 & 0,50 & 0,52 & 0,52 & 0,51 \\
\hline Refino de petróleo e coque & 0,55 & 0,54 & 0,52 & 0,51 & 0,53 & 0,53 \\
\hline $\begin{array}{l}\text { Eletricidade e gás, água, es- } \\
\text { goto e limpeza urbana }\end{array}$ & 0,63 & 0,62 & 0,59 & 0,58 & 0,60 & 0,60 \\
\hline Construção & 0,74 & 0,72 & 0,67 & 0,67 & 0,93 & 0,75 \\
\hline $\begin{array}{l}\text { Transporte, armazenagem } \\
\text { e correio }\end{array}$ & 0,77 & 0,75 & 0,74 & 0,77 & 0,82 & 0,77 \\
\hline $\begin{array}{l}\text { Serviços imobiliários e alu- } \\
\text { guel }\end{array}$ & 0,80 & 0,77 & 0,76 & 0,74 & 0,80 & 0,77 \\
\hline Alimentos e Bebidas & 0,87 & 0,83 & 0,83 & 0,84 & 0,87 & 0,85 \\
\hline $\begin{array}{l}\text { Serviços prestados às em- } \\
\text { presas }\end{array}$ & 0,86 & 0,87 & 0,84 & 0,90 & 0,96 & 0,89 \\
\hline Serviços de informação & 0,90 & 0,95 & 0,91 & 0,95 & 0,94 & 0,93 \\
\hline Comércio & 1,06 & 1,07 & 1,10 & 1,12 & 1,27 & 1,13 \\
\hline
\end{tabular}

Fonte: Elaboração própria. 
Os efeitos de choques na intermediação financeira sobre a produção dos setores foram capturados pelos Multiplicadores Financeiros Setoriais (MFS), originados da abordagem da Matriz de Contabilidade Social e Financeira (MCSF). Os resultados apontaram que o efeito de choques da intermediação financeira sobre o produto no Brasil, diferenciados por setores, é relevante para a decisão de estrutura de capital, indicando que o MFS deve ser associado a uma medida de restrição, aumentando a importância do estoque de dívida e seu custo de carregamento.

Ao considerar o MFS interagindo com o endividamento defasado (estoque de endividamento), observou-se que a inclusão do indicador leva a um aumento, na média, do coeficiente do estoque de dívida passada sobre o endividamento atual, o que indica menor velocidade de ajuste das empresas em direção a um novo nível de endividamento. Em nível das firmas, entretanto, quanto maior a interação do setor produtivo com o setor financeiro, mais essa restrição é aliviada. Ou seja, setores com maiores multiplicadores (maior relacionamento com o setor de intermediação financeira) apresentam inércia menor que os demais em seu grau de ajustamento.

Quanto às demais variáveis significativas no modelo, observa-se que as empresas aumentam seu nível de endividamento em momentos de hot market no mercado de dívidas, reforçando a hipótese de Market Timing, e que são mais endividadas as empresas em fase de maturidade (alta geração de fluxo de caixa, baixo risco e bluechips). Por outro lado, o constructo 'Tangibilidade' (obtido por Análise Fatorial) se mostrou negativamente relacionado com o endividamento, provavelmente pela forte participação da variável de benefícios fiscais não decorrentes da dívida no fator (como depreciação, que é bastante correlacionada ao nível de ativos tangíveis) no constructo.

Também a variável de turnover (giro do ativo) tem forte presença nele, sendo um dos componentes da lucratividade da firma e corroborando a relação negativa encontrada para o constructo 'Lucratividade'. Por fim, o custo da dívida se demonstrou positivamente relacionado ao nível de endividamento. Os resultados relativos à lucratividade e custo da dívida indicam que empresas que não têm acesso a lucros acumulados fazem uso de endividamento para honrar suas obrigações sempre que possível, pressionando o custo de tal financiamento e reforçando a complementariedade entre as teorias de trade-off e pecking order theory (empresas captam recursos externos quando há escassez de recursos internos e de acordo com suas características, em especial as relacionadas às garantias a serem oferecidas).

Por fim, destaca-se que os resultados se limitam às empresas de capital aberto com ações negociadas na $\mathrm{B} 3$, que o período observado se limita à disponibilidade das MCSF e às limitações das técnicas utilizadas. Como a proposta é inovadora, sugere-se que trabalhos adicionais sejam realizados utilizando variáveis geradas pela metodologia insumo-produto, pois esta se baseia nos fluxos efetivamente realizados, imprime informações sobre restrição financeira e, portanto, podem ajudar no entendimento não somente das decisões de estrutura de capital, mas também de outras questões de finanças corporativas ainda não analisadas. 


\section{Referências Bibliográficas}

Almeida, H. \& Campelo, M. (2007), 'Financial frictions and the substitution between internal e external funds', Journal of Financial and Quantitative Analysis 45(3), 589-622.

Anderson, T. W. \& Hsiao, C. (1982), 'Formulation and estimation of dynamic models using panel data', Journal of Econometrics 18(1), 47-82.

Baker, M. \& Wurgler, J. (2002), 'Market timing and capital structure', Journal of Finance 57(1), 1-30.

Berger, A. N. \& Udell, G. F. (1998), 'The economics of small business finance: the roles of private equity and debt markets in the financial growth cycle', Journal of Banking and Finance 22, 613-673.

Bradley, M., Jarrell, G. A. \& Kim, E. H. (1984), 'On the existence of optimal capital structure: Theory and evidence', Journal of Finance 39(3), 857-880.

Cook, D. O. \& Tang, T. (2010), 'Macroeconomic conditions and capital structure adjustment speed', Journal of Corporate Finance 16, 73-87.

Copat, R. \& Terra, P. R. S. (2009), 'Estrutura de Capital Internacional: Comparando América Latina e Estados Unidos', XXXIII Encontro Associação Nacional de Pesquisa em Administração. São Paulo: Anpad.

Correa, C. A., Basso, L. F. C. \& Nakamura, W. T. (2013), 'A estrutura de capital das maiores empresas brasileiras: Análise empírica das teorias de Pecking Order e Trade-Off, usando panel data', Revista de Administração Mackenzie 14(4), 106-133.

DeAngelo, H. \& Masulis, R. W. (1980), 'Optimal capital structure under corporate and personal taxation', Journal of Financial Economics 8(1), 3-29.

Durand, D. (1952), 'Cost of Debt and Equity Funds For Business: Trends and Problems of Measurement', Conference on Research in Business Finance. New York: National Bureau of Economic Research, p. 215-262.

Fama, E. F. \& French, K. R. (2002), 'Testing trade-off and pecking order predictions about dividends and debt', The Review of Financial Studies 15(1), 133.

Fazzari, S. M., Hubbard, R. G., Petersen, B. C., Blinder, A. S. \& Poterba, J. M. (1988), 'Financing constraints and corporative investments', Brookings Papers on Economic Activity 1, 146-206.

Fischer, E. O., Heinkel, R. \& Zechner, J. (1989), 'Dynamic capital structure choice: Theory and tests', The Journal of Finance 44, 19-40.

Flannery, M. J. \& Rangan, K. P. (2006), 'Partial adjustment toward target capital structures', Journal of Financial Economics 79(3), 469-506.

Fluck, Z., Holtz-Eakin, D. \& Rosen, H. S. (1998), 'Where does the money come from? The financing of small entrepreneurial enterprises', Metropolitan Studies program, Maxwell School of Citizenship and Public Affairs. Syracuse University. 
Frank, M. Z. \& Goyal, V. K. (2003), 'Testing the pecking order theory of capital structure', Journal of Financial Economics 67(2), 217-248.

Guilhoto, J. J. M. (2004), 'Análise de insumo produto: Teoria e fundamentos'.

Guilhoto, J. J. M., Sesso Filho, U. et al. (2005), Estimação da matriz insumoproduto a partir de dados preliminares das contas nacionais [estimation of input-output matrix using preliminary data from national accounts], Technical report, University Library of Munich, Germany.

Hair, J. J. (1998), Multivariate data analysis, 5 edn, Englewood Cliffs, NJ: Prentice Hall.

Harris, M. \& Raviv, A. (1991), 'The theory of capital structure', Journal of Finance 46(1), 297-355.

Jensen, M. \& Meckling, W. (n.d.), 'Theory of the firm: Managerial behavior, agency cost and ownership structure', Journal of Financial Economics . 3(4), 305-360.

Jiménez, J. I. C. (2007), 'Testes empíricos sobre market timing na estrutura de capital das empresas no Brasil', São Paulo: IBMEC. (Tese de Doutorado).

Kale, J. R. \& Shahrur, H. (2007), 'Corporate capital structure and the characteristics of suppliers and customers', Journal of Financial Economics 83(2), 321-365.

Kayo, E. K. \& Kimura, H. (2011), 'Hierarchical determinants of capital structure', Journal of Banking E Finance 35(2), 358-371.

La Porta, R., Lopez-de Silanes, F., Shleifer, A. \& Vishny, R. W. (1998), 'Law and finance', Journal of Political Economy 106(5), 1113-1155.

Leontief, W. (1936), 'Quantitative input-output relations in the economic system of the United States', Review of Economics and Statistics 18, 105-125.

MacKay, P. \& Philips, G. M. (2005), 'How does industry affect firm financial structures?', The Review of Financial Studies 18(4), 1433-1466.

Maksimovic, V. \& Zechner, J. (1991), 'Debt, agency costs, and industry equilibrium', The Journal of Finance 46(5), 1619-1643.

Martins, H. C. \& Terra, P. R. S. (2014), 'Determinantes nacionais e setoriais da estrutura de capital na América Latina', Revista de Administração e Contabilidade 18, 577-597.

Miller, R. \& Blair, P. (2009), Input-Output Analysis, 2 edn, Cambridge: Cambridge University Press.

Miyazawa, K. (1976), 'Input-output analysis and the structure of income distribution’, Berlin: Springer.

Modigliani, F. \& Miller, M. (1958), 'The cost of capital, corporation finance, and the theory of investment', American Economic Review . 48(3), 261-297.

Modigliani, F. \& Miller, M. (1963), 'Corporate income taxes and the cost of capital: a correction', American Economic Review 53(3), 433-443. 
Myers, S. C. (1984), 'The capital structure puzzle', Journal of Finance 39(3), 574-592.

Myers, S. \& Majluf, N. (1984), 'Corporate financing and investments decisions when firms have information that investors do not have', Journal of Financial Economics . 13(2), 187-221.

Oliveira, G. R., Tabak, B. M., Resende, J. G. \& Cajueiro, B. O. (2012), 'Determinantes da estrutura de capital das empresas brasileiras: uma abordagem em regressão quantílica', Brasília: Banco Central do Brasil. (Trabalhos para Discussão).

Perobelli, F. F. C. \& Fama, R. (2003), 'Fatores determinantes da estrutura de capital para empresas latino-americanas', Revista de Administração Contemporânea $7,9-35$.

Rajan, R. \& Zingales, L. (1995), 'What do we know about capital structure? some evidence from international data', Journal of Finance 50, 1421-1460.

Ross, S. A. (1977), 'The determination of financial structure: The incentivesignalling approach', The Bell Journal of Economics 8(1), 23-40.

Schwartz, E. \& Aronson, J. R. (1967), 'Some surrogate evidence in support of the concept of optimal financial structure', Journal of Finance 22, 10-18.

Shyam-Sunders, L. \& Myers, S. (1999), 'Testing static trade-off against pecking order models of capital structure', Journal of Financial Economics 51, 219-244.

Silveira, A. M. (2004), 'Governança corporativa e estrutura de propriedade: Determinantes e relação com o desempenho das empresas no Brasil', São Paulo: Faculdade de Economia, Administração e Contabilidade da Universidade de São Paulo. (Tese de Doutorado).

Titman, S. (1984), 'The effect of capital structure on a firm's liquidation decision', Journal of Financial Economics 13(1), 137-151.

Titman, S. \& Wessels, R. (1988), 'The determinants of capital structure choice', Journal of Finance 43, 1-19.

Warner, J. (1977), 'Bankruptcy costs: Some evidence', Journal of Finance . 32(2), 337-347.

Welch, I. (2011), 'Two common problems in capital structure research: The financial-debt-to-asset ratio and issuing activity versus leverage changes', International Review of Finance . 11(1), 1-17.

Zappa, P. A. (2011), 'Governança corporativa e a velocidade de ajuste da estrutura de capital das empresas brasileiras', Rio de Janeiro: Fundação Getúlio Vargas. (Dissertação de Mestrado). 